Egyptian Journal of Aquatic Biology \& Fisheries

Zoology Department, Faculty of Science,

Ain Shams University, Cairo, Egypt.

ISSN $1110-6131$

Vol. 25(4): 1129 - 1158 (2021)

www.ejabf.journals.ekb.eg

\title{
Qualitative and Quantitative Variability of Flora and Fauna along Rosetta Branch of the River Nile, Egypt
}

\author{
Usama M. Tahoun ${ }^{1}{ }^{*}$, Amany M. Haroon ${ }^{1}$, Heba E.A. Elsebaie ${ }^{1}$, Soaad A. Sabae ${ }^{1}$, \\ Walaa T. Hamza ${ }^{1}$ and Hesham R.A. Mola ${ }^{2}$ \\ 1. National Institute of Oceanography and Fisheries (NIOF), Cairo, Egypt \\ 2. Faculty of Education, Matrouh University, Marsa Matrouh, Egypt \\ *Corresponding Author: usamatahoun@yahoo.com
}

\section{ARTICLE INFO Article History:}

Received: March 8, 2021

Accepted: June 28, 2021

Online: Aug. 30, 2021

Keywords:

Macrophytes,

Microalgae,

Microbial assessment,

Zooplankton,

Micro invertebrates.

\begin{abstract}
During the last decades, the Rosetta branch of the River Nile received a great number of drainage wastes (domestic, agricultural, and industrial) that affected different aquatic organism's life. Accordingly, characterizing the biological aspects of this water body is necessary. The current study aims to survey the biodiversity of flora and fauna along the Rosetta branch to assess the environmental status of this area. Eight sites were selected along the Rosetta branch during 2018 for samples collection. Results indicated the presence of seven macrophyte species, dominated by the free-floating and emergent species Eichhornia crassipes and Echinochloa stagnina, respectively. Bacillariophyceae had the highest number of species compared with other groups of attached algae and occupied the first and the greatest predominance position. Epiphytic microinvertebrates associated with the floating plant Eichhornia crassipes recorded the highest numbers of species and groups during summer and the diversity was affected by the heavy load of pollution discharged to the Nile (especially at El-Rahawy region). Five groups of zooplankton (Rotifera, Copepoda, Cladocera, Meroplankton, and Protozoa) were documented and identified based on their morphological characters. High numbers of bacterial indicators of pollution exceeding the permissible limits were obtained, inferring the harmful effects of drains discharge on the water quality at the Rosetta branch. Physico-chemical parameters showed a great correlation between different biological aspects. The current study confirmed the effects of environmental factors on surveyed aquatic organisms, which could be used as a guide for evaluating water quality in the evaluated area.
\end{abstract}

\section{INTRODUCTION}

Nile River is the lifeline supplying water to millions of people. It extends into the Mediterranean Sea by its two main branches, the Rosetta and the Damietta, which are flowing through the Nile delta wetland (Badr et al., 2006). The Rosetta branch is receiving wastes discharged by agricultural, industrial, and domestic activities. A total of two pollution sources affecting the water quality at the Rosetta branch, firstly are the 
agricultural drains such as (El-Rahawy, Sabal, El-Tahreer, Tala, and Zawiet El-Bahr drains) and secondly are the direct continuous discharge of industrial wastes into the Rosetta branch. Therefore, it is important to make regular monitoring programs for the Rosetta branch (Donia, 2005).

Aquatic macrophytes are aquatic plants that remove toxic compounds from water and provide aquatic organisms with food, shelter, and substrates. Moreover, It is a source of some biologically active substances that have antimicrobial and anti-algal effects. (Fareed et al., 2008; Shaltout et al., 2010; Haroon and Abdel-Al, 2016; Haroon and Daboor, 2019; Haroon, 2020a, 2020b). Epiphytic microalgae determine the trophic status of aquatic ecosystems (Cook, 2007). It is considered as a good bioindicator because of fast reproduction rates and high sensitive responses to chemical variations and eutrophication (Larson et al., 2012). It is considered as a source of food for invertebrates and fish in the coastal zones (Abe et al., 2007). It is presence was depends on aquatic macrophytes as a host (Cattaneo et al., 1998). Epiphytes, with aquatic macrophytes, may utilize dissolved organic products released by their hosts.(Allen, 1971).

Microinvertebrates are the main source of the food for many fishes, it is responding rapidly to environmental changes because of the short generation times for most species. Different environmental factors affect the pattern of their distribution (Kimmel et al., 2006). It is served as bioindicators of water pollution (Mola, 2011; Ahmad et al., 2012). Rotifers, such as Brachionus species (as a food for many fish larvae), comprise a link in the food chains of inland water (Guerguess, 1993). Zooplankton species is playing as avital component of the aquatic biota, it is considered as an informative tool for exploring ecological changes in water. Also, it can transfer energy (from the producers to the consumers) constitutes the economic values of these biological resources in aquatic environments (Benítez-Díaz et al., 2014; EL-Sebaie et al., 2014). The total, fecal coliforms and fecal streptococci bacteria are used as bacterial indicators for estimating water pollution (Anufriieva et al., 2020).

Investigation of the biological aspects in the Rosetta branch will reflect the status of the water body. Documentation and characterization of the biological resources in the Rosetta branch will enable managing of this strategic Egyptian area properly in the future. Accordingly, the present study aimed to evaluate the flora and fauna communities structure (macrophytes, epiphytes, zooplankton, microinvertebrates, and bacteria) at the Rosetta branch, as well as monitoring the variations in these communities with the environmental conditions.

\section{MATERIALS AND METHODS}

\section{Area of investigation:}

The Rosetta branch (the main freshwater stream extending northwards, for about $236 \mathrm{~km}$ on the western boundary of the Nile Delta) is the central water source for several areas in the Nile Delta. 


\section{Sampling:}

Eight sampling locations, distributed along the Rosetta branch of the River Nile, were selected to collect samples during winter and summer 2018 (Table 1 \& Fig.1).

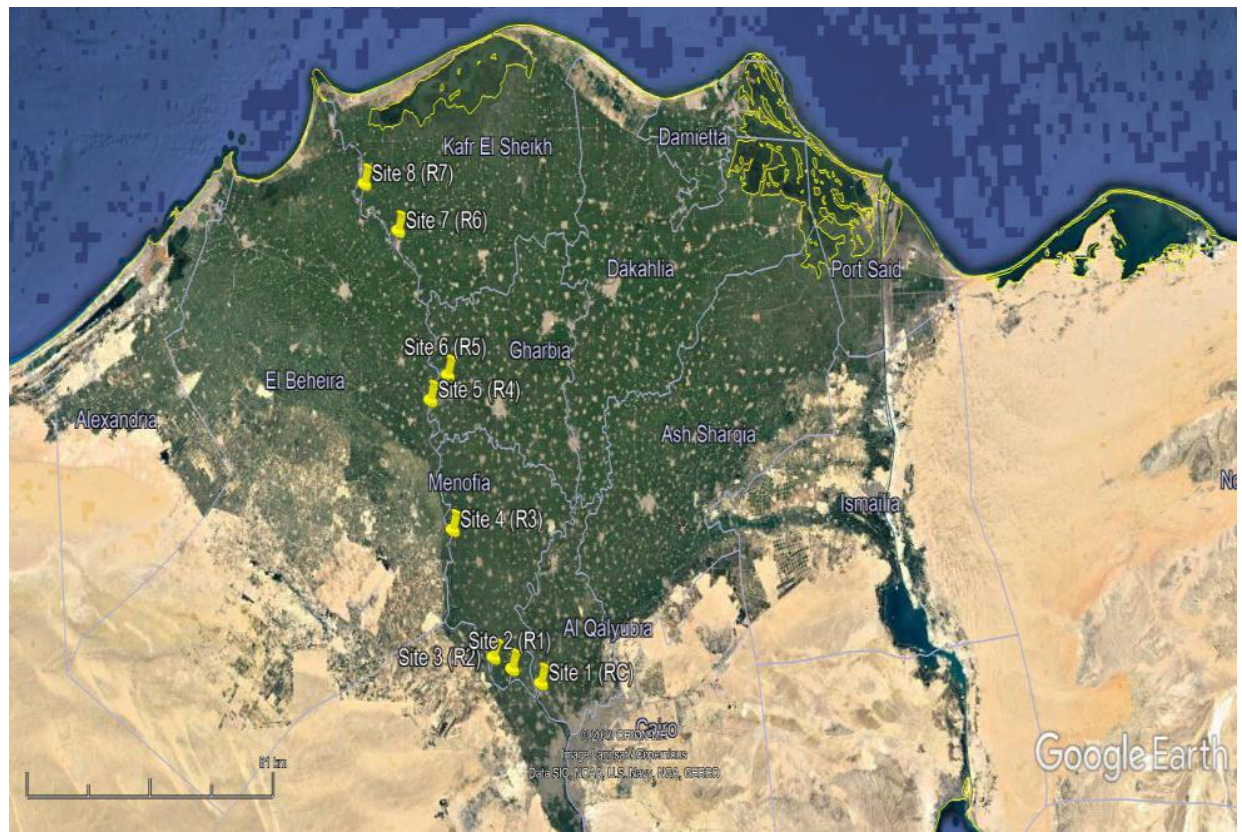

Fig.1. The map of selected sites at the Rosetta branch (Nile River).

Table 1: Sampling sites at the Rosetta branch.

\begin{tabular}{|c|c|c|c|}
\hline Site No. & Sations & Station code & Coordinates \\
\hline Site 1 & Al-Qanater Al-Khiria (Upstream El-Rahawy drain) & $\mathrm{RC}$ & $\begin{array}{c}30^{\circ} 12^{\prime} 48.79^{\prime \prime} \mathrm{N} \\
31^{\circ} 2^{\prime} 39.26^{\prime \prime} \mathrm{E}\end{array}$ \\
\hline Site 2 & El-Rahawy drain outfall & $\mathrm{R} 1$ & $\begin{array}{c}30^{\circ} 12^{\prime} 26.53^{\prime \prime} \mathrm{N} \\
31^{\circ} 1^{\prime} 57.84^{\prime \prime} \mathrm{E}\end{array}$ \\
\hline Site 3 & Al-qata (downstream El-Rahawy drain) & $\mathrm{R} 2$ & $\begin{array}{c}30^{\circ} 13^{\prime} 12.93^{\prime \prime} \mathrm{N} \\
30^{\circ} 58^{\prime} 33.77^{\prime \prime} \mathrm{E}\end{array}$ \\
\hline Site 4 & Tamalay & $\mathrm{R} 3$ & $\begin{array}{c}30^{\circ} 30^{\prime} 32.32^{\prime \prime} \mathrm{N} \\
30^{\circ} 49^{\prime} 57.29^{\prime \prime} \mathrm{E}\end{array}$ \\
\hline Site 5 & Kom Hamada & $\mathrm{R} 4$ & $\begin{array}{c}30^{\circ} 42^{\prime} 52.91^{\prime \prime} \mathrm{N} \\
30^{\circ} 45^{\prime} 44.28^{\prime \prime} \mathrm{E}\end{array}$ \\
\hline Site 6 & Kafer Al-Zayat & $\mathrm{R} 5$ & $\begin{array}{l}30^{\circ} 49^{\prime} 22.64^{\prime \prime} \mathrm{N} \\
30^{\circ} 48^{\prime} 38.93^{\prime \prime} \mathrm{E}\end{array}$ \\
\hline Site 7 & Dosouq & $\mathrm{R} 6$ & $\begin{array}{l}31^{\circ} 08^{\prime} 05.09^{\prime \prime} \mathrm{N} \\
30^{\circ} 38^{\prime} 01.26^{\prime \prime} \mathrm{E}\end{array}$ \\
\hline Site 8 & Fowah (Kafer Al-Sheikh) & $\mathrm{R} 7$ & $\begin{array}{l}31^{\circ} 12^{\prime} 00.67^{\prime \prime} \mathrm{N} \\
30^{\circ} 33^{\prime} 11.18^{\prime \prime} \mathrm{E}\end{array}$ \\
\hline
\end{tabular}

\section{Macrophytes collection and identification:}

At each location, a quadrate of $50 \times 50 \mathrm{~cm}$ was used and the macrophytes inside each quadrate were collected. The emergent macrophytes were translocated in polyethylene bags (without water), whereas the submerged and free-floating species were saved in water. Based on Boulos (2005), macrophytes were identified and separated into different taxa. The macrophyte samples were weighted (to estimate their biomass 
production). The results were expressed as kilogram per square meter wet weight $\left(\mathrm{kg} / \mathrm{m}^{2}\right.$ ww) (Misra, 1968).

\section{Epiphytic algal collection and identification:}

Eichhornia crassipes (Mart.) Solms-Laubach was chosen for sampling as it was the most dominant macrophyte. After macrophyte collection, submerged parts of Eichhornia crassipes were cut near the bottom -just above the roots-, gently left out from the water, and were divided into about six sections. In the laboratory, the periphytons -on the macrophyte sections- were scraped off many times with a toothbrush in the same day or one day after. Subsequently, the plant segments were washed with tap water. The periphyton algae-water suspension was poured into 1-liter glass cylinder and passed through a $300 \mu \mathrm{m}$ mesh, for avoiding contamination by small macrophyte fragments (Cattaneo et al., 1997), till the volume of $1000 \mathrm{ml}$. To facilitate sedimentation and stain of algal cells, Lugol's iodine solution was added (until the color changed to faint tea color). The preserved samples were lifted for 5 days to settle (APHA, 2012). The supernatant was carefully siphoned off with a small plastic tube ending with a fine net, 20 $\mu \mathrm{m}$ mesh diameter until the samples were concentrated to about $50 \mathrm{ml}$. The remaining volume was adjusted to $50 \mathrm{ml}$ and kept at $4^{\circ} \mathrm{C}$ in a dark plastic vial until microscopic examination. Epiphytic algal counts were done using a wild inverted microscope (Zeiss, Axiovert $25 \mathrm{C}$ ), where $5 \mu \mathrm{L}$ of the reduced volume was placed in a counting chamber and examined at 10X eyepiece and 40X objective. The drop method (APHA, 2012) was applied for both counting and identifying different algal species from different samples. Cleve- Euler,1952; Bourrelly, 1968; Starmach, 1968; Prescott, 1978; Mizuno, 1990 were used for epiphyte identification.

\section{Microinvertebrates collection and identification:}

To collect microinvertebrates, Eichhornia crassipes were collected, placed in polyethylene bags (with filtered water), and fixed with neutral formalin solution (10\%). The submerged parts of Eichhornia crassipes were placed (separately) in a plastic bottle (containing filtered water). The bottle was closed and shacked to detach all animals from Eichhornia crassipes. The epiphytic microinvertebrates were separated with a net of 500$\mu \mathrm{m}$ mesh size, placed into a labeled plankton bottle, and fixed with $10 \%$ neutral formalin solution. By using a Trinuclear microscope, the microinvertebrates were separated into groups. Specimens were investigated, classified and counted as described by Edmondson, 1966; Pennak, 1978; Shehata et al.( 1998 a; 1998 b); Dang et al., 2015. The plants were dried (at $60{ }^{\circ} \mathrm{C}$ ) in the oven for three days and weighted. The densities of the animal attached to plants were expressed as the number of individuals per gram dry weight plant (org./g plant dw) of the macrophytes (Arora and Mehra, 2003; Sakuma et al. 2002).

\section{Zooplankton Sampling, counting and characterization:}

Samples were collected as described by Saad $\boldsymbol{e t}$ al., 2013. Zooplankton samples were immediately preserved and counted according to Mageed (2005). All the organisms 
in each sample were characterized to species level as possible. Samples were made up to (100 ml) standard volume. $1 \mathrm{ml}$ was used to count the organisms (using a binocular microscope) according to Shiel and Koste (1992); Einsle (1996); Smirnov (1996) with some modifications as described by Saad et al. (2013). Shannon-Winner diversity, species richness, evenness, and similarity index were calculated using Primer (Vs5) program (Saad et al., 2013). Also, the PAST software was used for constructing the clustering analysis among the evaluated stations.

\section{Bacteriology:}

Total bacterial count (enumerated at $22^{\circ} \mathrm{C}$ and $37^{\circ} \mathrm{C}$ ) were detected using the pour plate technique on the nutrient agar media according to APHA, 2012. Total and fecal coliforms bacteria (TC and FC) were enumerated by MPN technique (the Most Probable Number). MacConkey broth media was used for standard presumptive test. tubes were incubated at $37{ }^{\circ} \mathrm{C}$ for $48 \mathrm{hrs}$ (for total coliform bacteria) and at $44{ }^{\circ} \mathrm{C}$ for $24 \mathrm{hrs}$ (in water bath for fecal coliform bacteria). Confirmation for positive tubes by streaked on EMB media (Eosin Methylene Blue agar) then incubated at $37{ }^{\circ} \mathrm{C}$ for $24 \mathrm{hrs}$ according to (APHA, 2005). Fecal streptococci bacteria (FS) were also enumerated by the MPN technique using ADB media (Azide Dextrose Broth) for presumptive test and a positive tubes showing turbidity after 2 days at $37{ }^{\circ} \mathrm{C}$. Confirmation by transferring positive tubes to ethyl violet azide broth media and a positive tubes showing turbidity and sedimentation on the bottom within $48 \mathrm{hrs}$ at $37^{\circ} \mathrm{C}$ (APHA, 2005).

Escherichia coli and Staphylococcus aureus were enumerated by the Membrane filtration (MF) technique, a suitable volume was filtered through $0.45 \mu \mathrm{m}$ membrane filter. Filtrates were transferred into EMB agar medium (Eosin Methylene Blue) for $E$. coli and MSA agar medium (Mannitol salt agar) for $S$. aureus. Plates were incubated at $44.5^{\circ} \mathrm{C}$ for $24 \mathrm{hrs}$ (for E. coli) and $37^{\circ} \mathrm{C}$ for $24-48 \mathrm{hrs}$ (for $S$. aureus). Positive results for $E$. coli and $S$. aureus colonies were enumerated (green metallic sheen and yellow colonies respectively). (APHA, 2012). Pseudomonas aeruginosa was enumerated by MPN method using L.asparagine broth medium and the green fluorescent pigment indicated a positive result, then plates of Cetrimide agar media were inoculated from positive tubes, incubated at $37^{\circ} \mathrm{C}$ for $24-48 \mathrm{hrs}$. Confirmation was detected by producing yellow-green to blue-green color colonies according to (Balkhair, 2016).

$$
\begin{aligned}
& \text { E. coli } / 100 \mathrm{ml}=\frac{\text { Number of E.coli colonies } \times 100}{\text { Volume of sample filtered }(\mathrm{ml})} \\
& \text { S. aureus } / 100 \mathrm{ml}=\frac{\text { Number of S.aureus colonies } \times 100}{\text { Volume of sample filtered (ml) }}
\end{aligned}
$$

Salmonella sp.and Shigella sp.were detected by the Membrane filtration (MF) technique, $100 \mathrm{ml}$ of water samples were filtered through $0.45 \mu \mathrm{m}$ filter paper, and for Salmonella sp. was transferred to tetrathionate broth media and incubated at $43^{\circ} \mathrm{C}$ up to 5 days with repeated streaking on Salmonella-Shigella (S-S) agar medium at $35^{\circ} \mathrm{C}$ for 24 hrs. Black-centered colorless colonies on S-S agar media refer to a positive result, while Shigella sp. was transferred to nutrient broth media and incubated for $6 \mathrm{hrs}$ at $35^{\circ} \mathrm{C}$, then 
isolates were cultivated on S-S agar media at $35^{\circ} \mathrm{C}$ overnight. Colorless colonies refer to a positive result. Identification of Salmonella sp.and Shigella sp. were carried out according to Robert and Noel (1981); APHA (2005). Detection of Vibrio cholerae occured after samples concentrated by filtration $(0.2-\mu \mathrm{m})$. Overnight enrichment was performed using APW (alkaline peptone water) at $\mathrm{pH}$ 8.6. Surface aliquots are streaked onto TCBS agar media (Thiosulfate Citrate Bile Sucrose) according to Koch (1994) Identification of $V$. cholera was carried out according to APHA (2005).

\section{Physico-chemical characterization:}

Physico-chemical parameters were analyzed at chemical laboratories (NIOF) according to the standard methods (APHA, 2005).

\section{Data processing:}

Statistical analysis was processed for data by Principal component analysis (PCA) to correlate physicochemical parameters in water with different biological aspects using the XL STAT program 2020.

\section{RESULTS}

\section{Macrophytes distribution and community structure}

According to the data mentioned in Table (2), seven species of aquatic macrophytes belonging to seven genera related to 7 families were recorded. They were classified ecologically into three major groups (viz; sub-merged, floating, and emergent hydrophytes). The sub-merged hydrophytes were represented by Myriophyllum spicatum and Ceratophyllum demersum. During winter the two species were recorded at three sites (RC, R5, R7), and Ceratophyllum demersumwas recorded at R 1 and R7, however, during summer Myriophyllum spicatum was the only recorded species. Floating hydrophytes were represented by two species (Eichhornia crassipes and Potamogeton nodosus). In which, Eichhornia crassipes were recorded at all sampling sites (Percentage $=100 \%$ of sampling sites), however, Potamogeton nodosus was recorded at only one site (site R5). Emergent hydrophytes represented by Polygonum tomentosum (L.), Cyperus alopecuroides Rottb.(Per) and Echinochloa stagnina (Retz.) P. Beauv. (Per). During winter Echinochloa stagnina was recorded in 5 sites (RC, R2, R3, R4, R5), however, during summer it was found in only three sites ( $\mathrm{RC}, \mathrm{R} 6, \mathrm{R} 7)$. The other two species were less frequent (Table 3).

Table 2: Classification of the macrophytes recorded at the Rosetta branch.

\begin{tabular}{|c|c|}
\hline Scientific name & Family \\
\hline Ceratophyllum demersum L. & Ceratophyllaceae \\
\hline Cyperus alopecuroides Rottb.(Per) & Cyperaceae \\
\hline Myriophyllum spicatum L. & Haloragaceae \\
\hline Potamogeton nodosus Poir & Potamogetonaceae \\
\hline Polygonum tomentosum L. & Polygonaceae \\
\hline Echinochloa stagnina (Retz.) P. Beauv. (Per) & Poacea (Gramineae) \\
\hline Eichhornia crassipes (Mart.) Solms & Pontederiaceae \\
\hline
\end{tabular}


Comparing the two studied seasons, winter was the richest season in species number (7 species), and site RC was the richest site (5 species) (Table 3). During this season two submerged macrophytes species were detected, however, during summer this group of macrophytes was represented by only one species, with the highest percentage for Myriophyllum spicatum (percentage $=37.5$ and $25.0 \%$ of the total sampling sites for the two seasons respectively). However Ceratophyllum demersum L. was the least frequent species present (Table 3). Throughout the two studied seasons Eichhornia crassipes (floating macrophytes) and recorded widely distributed and were considered the most dominant species (100\%). Echinochloa stagnina (emergent macrophytes) was registered widely distributed and the most dominant species were found in $62.5 \%$ and $37.5 \%$ of the total sampling sites for the two seasons respectively.

Table 3: Floristic composition of the different sites at the Rosetta Branch.

\begin{tabular}{|c|c|c|c|c|c|c|c|c|c|c|c|c|}
\hline \multirow{2}{*}{ Season } & \multirow{2}{*}{ Species } & \multirow{2}{*}{ Life form } & \multicolumn{8}{|c|}{ Ecological sites } & \multirow{2}{*}{ NS } & \multirow{2}{*}{$\mathbf{P} \%$} \\
\hline & & & $\mathbf{R C}$ & R1 & $\mathbf{R 2}$ & R3 & $\mathbf{R 4}$ & $\mathbf{R 5}$ & R6 & R7 & & \\
\hline \multirow{9}{*}{ 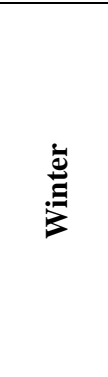 } & Submerged & & & & & & & & & & & \\
\hline & Myriophyllum spicatum L. & Hy & + & - & - & - & - & + & - & + & 3 & 37.5 \\
\hline & Ceratophyllum demersum $\mathrm{L}$. & Hy & & + & - & - & - & + & - & + & 3 & 37.5 \\
\hline & Floating & & & & & & & & & & & \\
\hline & Eichhornia crassipes (Mart.) Solms & Hy & + & + & + & + & + & + & + & + & 8 & 100 \\
\hline & Potamogeton nodosus Poir. & Hy & & - & - & - & - & + & - & & 1 & 12.5 \\
\hline & $\begin{array}{l}\text { Emergent } \\
\text { Echinochloa stagnina (Retz.) P. Beauv. (Per) }\end{array}$ & $\mathrm{G}, \mathrm{He}$ & + & - & + & + & + & + & - & - & 5 & 62.5 \\
\hline & Cyperus alopecuroides Rottb.(Per) & $\mathrm{G}, \mathrm{He}$ & + & - & - & + & - & - & - & - & 2 & 25.0 \\
\hline & Polygonum tomentosum $\mathrm{L}$ & $\mathrm{G}, \mathrm{He}$ & + & + & + & - & - & - & - & + & 4 & 50.0 \\
\hline \multirow{10}{*}{ 离 } & Submerged & & & & & & & & & & & \\
\hline & Myriophyllum spicatum L. & Hy & + & - & - & - & - & - & - & + & 2 & 25.0 \\
\hline & Ceratophyllum demersum $\mathrm{L}$. & Hy & & - & - & - & - & - & - & & 0 & 0.0 \\
\hline & Floating & & & & & & & & & & & \\
\hline & Eichhornia crassipes (Mart.) Solms & Hy & + & + & + & + & + & + & + & + & 8 & 100 \\
\hline & Potamogeton nodosus Poir. & Hy & & - & - & - & - & - & - & + & 1 & 12.5 \\
\hline & Emergent & & & & & & & & & & & \\
\hline & Echinochloa stagnina (Retz.) P. Beauv. (Per) & $\mathrm{G}, \mathrm{He}$ & + & - & - & - & - & - & + & + & 3 & 37.5 \\
\hline & Cyperus alopecuroides Rottb.(Per) & $\mathrm{G}, \mathrm{He}$ & & - & - & - & - & - & - & + & 1 & 12.5 \\
\hline & Polygonum tomentosum $\mathrm{L}$ & $\mathrm{G}, \mathrm{He}$ & + & - & - & - & - & - & - & + & 2 & 25.0 \\
\hline
\end{tabular}

NS = Number of sites in which the plants is recorded; P\% = Presence percentage; life-form: $\mathrm{G}=\mathrm{Geophytes,} \mathrm{He}$ = Helophytes, Hy = Hydrophytes. 


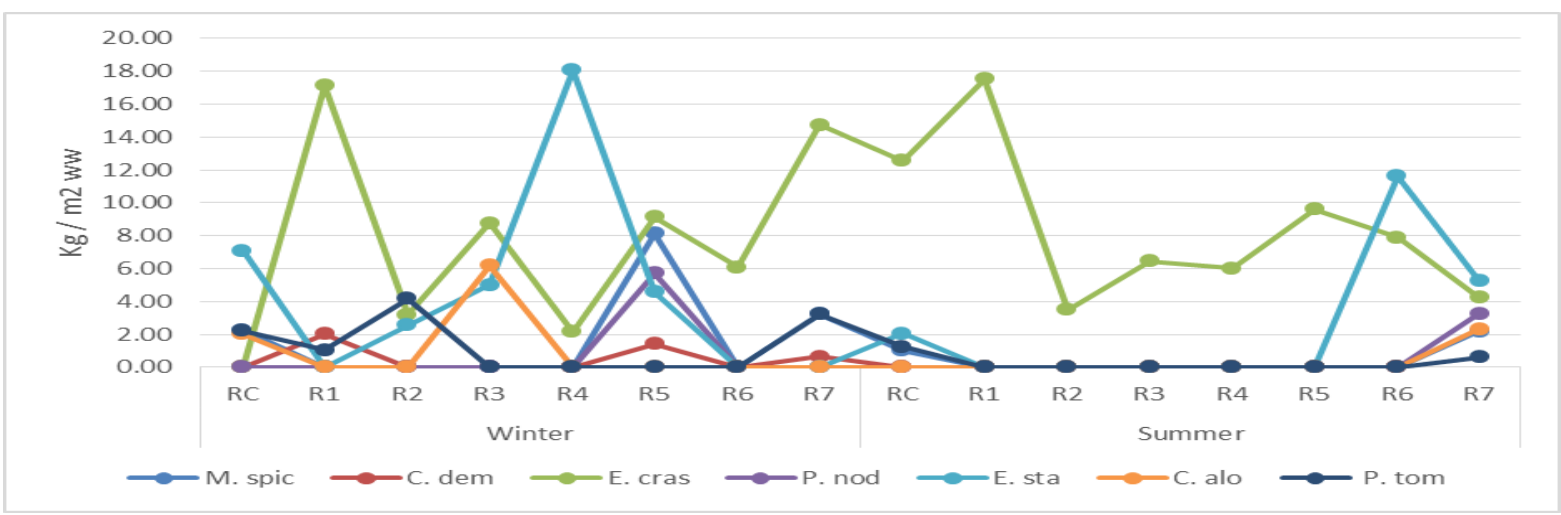

Fig.2. Biomass production values of different macrophytes species

M. spic $=$ Myriophyllum spicatum, $C$. dem $=$ Ceratophyllum demersum, $E$. cras =Eichhornia crassipes, $P$. nod $=$ Potamogeton nodosus, E. sta $=$ Echinochloa stagnina, $C$. alo =Cyperus alopecuroides and $P$. tom= Polygonum tomentosum

The standing crop data (Fig.2) of the collected macrophytes showed a considerable seasonal and spatial variation. During the whole study period, the emergent macrophyte species Echinochloa stagnina recorded the highest biomass production value $\left(18.06 \mathrm{~kg} / \mathrm{m}^{2} \mathrm{ww}\right)$ at site R4, followed by the free-floating species Eichhornia crassipes $\left(17.14 \mathrm{~kg} / \mathrm{m}^{2} \mathrm{ww}\right)$ from site $\mathrm{R} 1$. However, during summer, the highest value was recorded for Eichhornia crassipes being $17.54 \mathrm{~kg} / \mathrm{m}^{2}$ ww from the same site. The other five species showed very low production values.

\section{Epiphytic micro-algae}

A total of 294 of epiphytic algal species were charachterized and identified (Bacillariophyceae 122 spp., Chlorophyceae 109 spp., Cyanophyceae 46 spp., Dinophyceae 6 spp., Euglenophyceae 6 spp., Cryptophyceae 5 spp., and Xanthophyceae $1 \mathrm{sp}$.$) .$

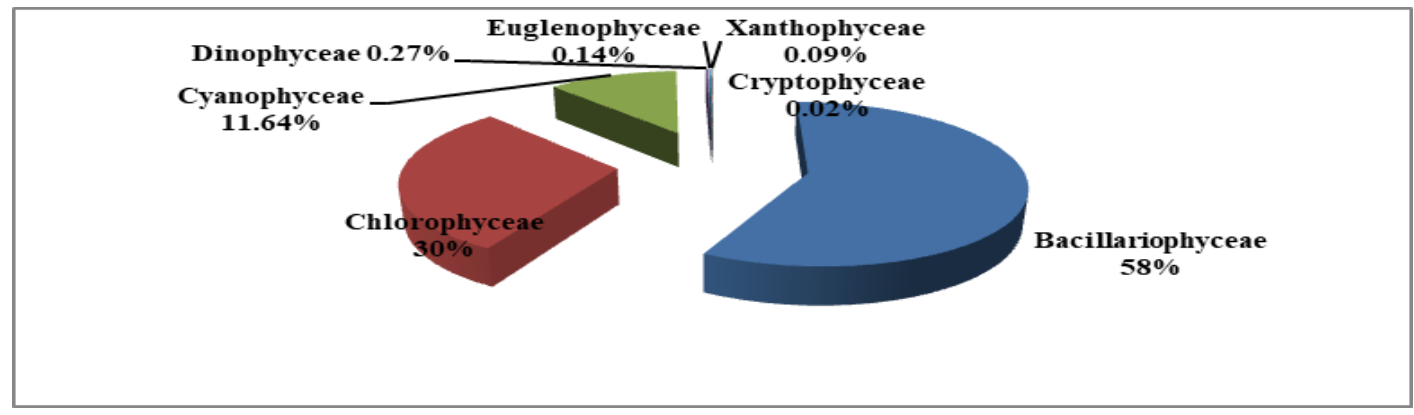

Fig.3: Percentage of epiphytic algal classes at the Rosetta branch. 


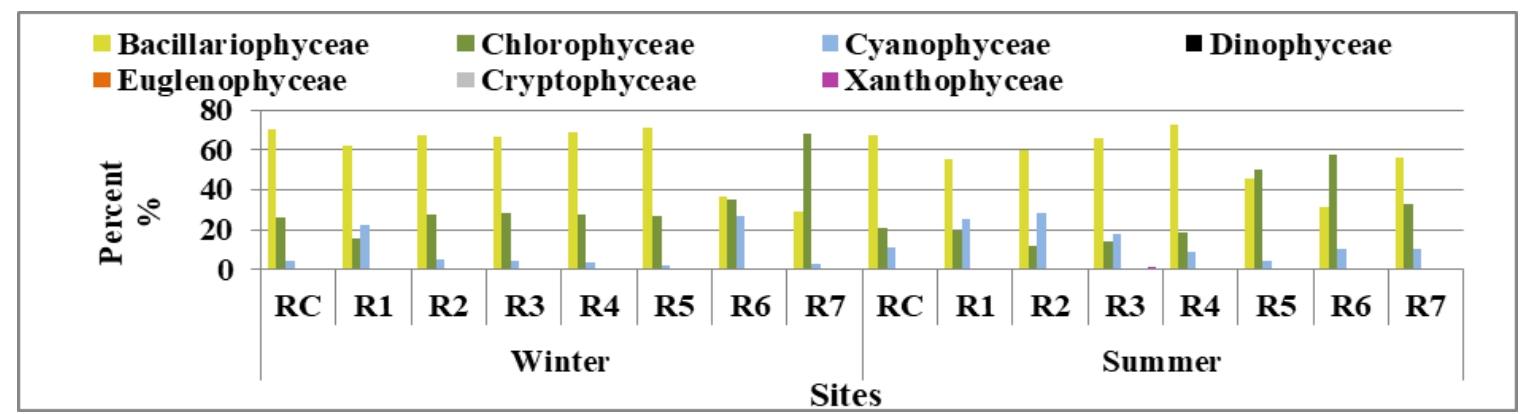

Fig. 4: Percentage of epiphytic algal classes at the Rosetta baranch.

Bacillariophyceae had the highest number of species compared with other groups of attached algae. The percentage of epiphyte algae varied according to sites and seasons. Bacillariophyceae occupied the first and the greatest predominance position (58 $\%$ ) followed by greens (30 \%), blue-greens (11.64 \%), Dinophyceae $(0.27 \%)$, Euglenophyceae $(0.14 \%)$, Xanthophyceae $(0.09 \%)$ and Cryptophyceae $(0.02 \%)$, ( Figs. $3 \& 4)$. In the present study, the most dominant diatom species were Fragilaria construns (its highest percentage was 49.9 at site 4 during summer), Cyclotella ocellata (17.6\% at site 3 during summer), and Cyclotella meneghiniana (11\% at site 1 during winter) (Table 4). Chlorophyceae was dominated by Ankistrodesmus fusiformis, Coelastrum sphaericum, Scenedesmus ecornis, and Scenedesmus quadricauda (Table 5). Oedogonium sp. made the peak of green epiphytes only during summer at sites $5 \& 6$. Cyanophyceae was dominated by Leptolyngbya perelegans, Lyngbya limnetica, Microcystis aeruginosa, and Phormidium sp.

Table 4: Most dominant epiphytic diatoms and occurrence percentage at the Rosetta branch

\begin{tabular}{|c|c|c|c|c|c|c|c|c|c|c|c|c|c|c|c|c|}
\hline \multirow[b]{2}{*}{ dominant diatoms } & \multicolumn{8}{|c|}{ Winter } & \multicolumn{8}{|c|}{ Summer } \\
\hline & $\mathbf{R C}$ & R1 & $\mathbf{R 2}$ & R3 & $\mathbf{R 4}$ & R5 & R6 & R7 & $\mathbf{R C}$ & R1 & $\mathbf{R 2}$ & $\mathbf{R 3}$ & R4 & R5 & R6 & $\mathbf{R} 7$ \\
\hline Cyclotella meneghiniana & 4 & 11 & 6.2 & 4.4 & 4.9 & 10.9 & 5.4 & 3.4 & 4.8 & 8.2 & 9.6 & 3.5 & 4.3 & 3.7 & 7.7 & 6.2 \\
\hline Cyclotella ocellata & 2.7 & 5.2 & 9.5 & 9.3 & 8.7 & 9.5 & 4.3 & 2.7 & 6.0 & 7.1 & 7.2 & 17.6 & 0.0 & 7.5 & 0.0 & 0.0 \\
\hline Cyclotella operculata & 0 & 1.8 & 0.4 & 0.0 & 3.6 & 4.1 & 2.2 & 4.1 & 2.2 & 3.4 & 5.3 & 2.0 & 0.0 & 3.4 & 3.1 & 4.0 \\
\hline Fragilaria construns & 3.6 & 0.5 & 0.4 & 3.3 & 3.5 & 0.0 & 4.0 & 0.0 & 4.7 & 0.0 & 0.0 & 0.0 & 49.9 & 0.0 & 0.0 & 10.4 \\
\hline Melosira granulata & 4.3 & 8 & 5.0 & 2.6 & 6.1 & 8.2 & 0.7 & 1.0 & 1.2 & 3.8 & 2.4 & 3.5 & 0.0 & 3.7 & 2.3 & 0.0 \\
\hline Nitzschia holastica & 4.6 & 8.8 & 6.4 & 5.5 & 5.8 & 10.9 & 7.2 & 1.7 & 0.0 & 0.0 & 0.3 & 0.0 & 0.0 & 0.6 & 0.0 & 0.0 \\
\hline Nitzschia palea & 0 & 6.91 & 2.0 & 5.5 & 3.3 & 6.8 & 0.0 & 0.0 & 0.0 & 4.2 & 0.0 & 0.0 & 4.3 & 1.5 & 1.5 & 6.2 \\
\hline Syndra ulna & 0.7 & 0 & 0.0 & 0.0 & 0.0 & 0.0 & 0.0 & 0.0 & 1.0 & 2.0 & 1.5 & 4.0 & 2.4 & 3.0 & 0.0 & 0.0 \\
\hline \multicolumn{17}{|l|}{ dominant greens } \\
\hline Ankistrodesmus fusiformis & 3 & 6.2 & 2.0 & 19.5 & 4.0 & 6.4 & 2.0 & 0.0 & 0.0 & 5.0 & 15.0 & 0.0 & 0.0 & 0.0 & 0.0 & 0.0 \\
\hline Coelastrum sphaericum & 0.4 & 7 & 5.8 & 0.0 & 0.0 & 0.0 & 10.2 & 4.2 & 0.0 & 1.0 & 0.0 & 0.0 & 0.0 & 0.0 & 3.0 & 2.3 \\
\hline Oedogonium sp. & 0 & 0 & 0.0 & 0.0 & 0.0 & 0.0 & 0.0 & 0.0 & 0.0 & 25.5 & 0.0 & 0.0 & 0.0 & 0.0 & 22.4 & 30.7 \\
\hline Planktonema lauterbornii & 0 & 3 & 1.6 & 0.0 & 0.0 & 0.0 & 8.5 & 2.0 & 0.0 & 5.9 & 4.3 & 0.0 & 0.0 & 5.7 & 0.0 & 0.0 \\
\hline Scenedesmus ecornis & 2.1 & 3 & 3.7 & 4.9 & 1.6 & 2.2 & 1.0 & 3.2 & 0.0 & 3.7 & 0.0 & 0.7 & 0.0 & 0.0 & 4.5 & 3.8 \\
\hline Scenedesmus dimorphus & 0 & 7 & 2.8 & 0.0 & 0.0 & 0.0 & 8.5 & 3.1 & 0.0 & 2.0 & 0.0 & 1.0 & 0.7 & 0.0 & 2.2 & 3.1 \\
\hline Scenedesmus quadricauda & 2 & 5.2 & 4.4 & 0.0 & 0.0 & 2.2 & 6.8 & 0.0 & 4.4 & 5.2 & 3.2 & 2.9 & 5.3 & 7.1 & 0.7 & 4.6 \\
\hline \multicolumn{17}{|l|}{ dominant blue greens } \\
\hline Chroococcus turgidus & 0.1 & 0.5 & 0.0 & 0.0 & 9.0 & 0.0 & 1.0 & 0.2 & 0.1 & 0.7 & 0.2 & 1.4 & 0.0 & 0.0 & 0.0 & 0.0 \\
\hline Cylindrospermopsis raciboroskii & 0 & 0.6 & 2.0 & 0.7 & 0.0 & 0.0 & 0.0 & 0.0 & 0.7 & 3.8 & 1.2 & 0.0 & 0.0 & 0.7 & 3.8 & 0.0 \\
\hline Leptolyngbya perelegans & 0 & 0.5 & 0.0 & 1.5 & 0.0 & 0.0 & 0.0 & 0.0 & 5.0 & 4.9 & 11.5 & 7.0 & 4.3 & 0.0 & 0.0 & 4.2 \\
\hline Lyngbya limnetica & 1.7 & 19 & 2.4 & 1.3 & 1.0 & 1.0 & 18.0 & 1.5 & 1.1 & 7.8 & 8.7 & 6.3 & 0.0 & 1.5 & 2.3 & 0.0 \\
\hline
\end{tabular}




\begin{tabular}{|c|c|c|c|c|c|c|c|c|c|c|c|c|c|c|c|c|}
\hline Microcystis aeruginosa & 0.2 & 0.9 & 0.2 & 0.0 & 0.0 & 0.0 & 0.3 & 0.1 & 0.0 & 2.1 & 1.0 & 1.8 & 0.0 & 0.0 & 0.0 & 0.0 \\
\hline Phormidium sp. & 0 & 0.9 & 0.2 & 0.9 & 0.0 & 0.3 & 0.0 & 0.0 & 0.0 & 4.0 & 4.8 & 0.0 & 0.0 & 2.2 & 3.8 & 0.0 \\
\hline Planktothrix agardhii & 0 & 3.5 & 0.0 & 0.0 & 0.0 & 0.5 & .3 .8 & 0.3 & 0.0 & 5.3 & 0.0 & 0.0 & 4.3 & 0.0 & 0.0 & 6.2 \\
\hline
\end{tabular}

Table 5: List of epiphytic algal species recorded at the Rosetta branch

\begin{tabular}{|c|c|c|c|}
\hline \multicolumn{4}{|l|}{ Bacillariophyceae } \\
\hline $\begin{array}{l}\text { Achnanthes brevipes } \mathrm{C} \text {. } \\
\text { Agardh }\end{array}$ & $\begin{array}{l}\text { Diploneis smithii (Brébisson) } \\
\text { Cleve }\end{array}$ & Navicula cryptocephala Kutz & Nitzschia holastica Hust. \\
\hline Achnanthes lanceolata & Eunotia veneris (Kützing) De & Navicula cryptocephala var. & Nitzschia ignorata \\
\hline Breb. & Toni & veneter (Kutz.) Grun & Krasske \\
\hline $\begin{array}{l}\text { Achnanthes } \\
\text { oestrupi (H.Bachm.\& } \\
\text { A.Cleve) Hustedt }\end{array}$ & Eunotia sp. & $\begin{array}{l}\text { Navicula cryptocephala var. } \\
\text { intermedia Gran. }\end{array}$ & $\begin{array}{l}\text { Nitzschia kutzingiana } \\
\text { Hilse }\end{array}$ \\
\hline $\begin{array}{l}\text { Aanthocerus zachariasii } \\
\text { (Brun)Simonsen }\end{array}$ & $\begin{array}{l}\text { Epithemia argus (Ehrenberg) } \\
\text { Kützing }\end{array}$ & Navicula cuspidata Kutzing & $\begin{array}{l}\text { Nitzschia linearis } \mathrm{W} \text {. } \\
\text { Smith }\end{array}$ \\
\hline Amphora ovalis kutz. & $\begin{array}{l}\text { Fragilaria construns (Ehr.) } \\
\text { Grun }\end{array}$ & $\begin{array}{l}\text { Navicula exigua (Gregory) O. } \\
\text { Muller }\end{array}$ & $\begin{array}{l}\text { Nitzschia obtusa var. } \\
\text { scalpelliformis Grunow }\end{array}$ \\
\hline $\begin{array}{l}\text { Asterionella formosa } \\
\text { Hassall }\end{array}$ & $\begin{array}{l}\text { Fragilaria construns var. } \\
\text { veneter (Ehr.) Grun }\end{array}$ & Navicula festiva Krasske & $\begin{array}{l}\text { Nitzschia ovalis } \\
\text { H.J.Arnott }\end{array}$ \\
\hline $\begin{array}{l}\text { Bacillaria paradoxa } \\
\text { J.F.Gmelin in Linnaeus }\end{array}$ & Fragilaria crotonensis Kitton & Navicula helvetica (Brun) & $\begin{array}{l}\text { Nitzschia palea (Kutz.) } \\
\text { W. Smith }\end{array}$ \\
\hline Biddulphia laevis Ehrenberg & $\begin{array}{l}\text { Fragilaria inflata (Heiden) } \\
\text { Hustedt }\end{array}$ & $\begin{array}{l}\text { Navicula lanceolata } \\
\text { Ehrenberg }\end{array}$ & Nitzschia paleacae Grum \\
\hline $\begin{array}{l}\text { Caloneis permagna (Bailey) } \\
\text { Cleve }\end{array}$ & Fragilaria sp. & Navicula luzonensis Hustedt & $\begin{array}{l}\text { Nitzschia recta Hantzsch } \\
\text { ex Rabenhorst }\end{array}$ \\
\hline $\begin{array}{l}\text { Campylodiscus clypeus } \\
\text { Ehrenberg ex Kützing }\end{array}$ & Fragilaria virescens Ralfs & Navicula punctulata W.Smith & $\begin{array}{l}\text { Nitzschia sigmoidea } \\
\text { (Nitzsch) W.Smith }\end{array}$ \\
\hline $\begin{array}{l}\text { Cocconeis diminuta } \\
\text { Pantocsek }\end{array}$ & $\begin{array}{l}\text { Gomphonema apicatum } \\
\text { Ehrenberg }\end{array}$ & Navicula pupula Kutz. & $\begin{array}{l}\text { Nitzschia stagnorum } \\
\text { Rabenhorst }\end{array}$ \\
\hline $\begin{array}{l}\text { Cocconies placentula } \\
\text { Ehrenberg }\end{array}$ & $\begin{array}{l}\text { Gomphonema augur } \\
\text { Ehrenberg }\end{array}$ & $\begin{array}{l}\text { Navicula rhyncocephala } \\
\text { Kützing }\end{array}$ & $\begin{array}{l}\text { Nitzschia sublinearis } \\
\text { Hustedt }\end{array}$ \\
\hline $\begin{array}{l}\text { Cocconeis placentula var. } \\
\text { lineata (Ehrenberg) Van } \\
\text { Heurck }\end{array}$ & $\begin{array}{l}\text { Gomphonema olivaceum } \\
\text { (Langb.)Kutz }\end{array}$ & Navicula salinarum Grunow & $\begin{array}{l}\text { Nitzschia subtilis } \\
\text { (Kützing) Grunow }\end{array}$ \\
\hline $\begin{array}{l}\text { Cocconeis placentula var. } \\
\text { skvortzowii (Skv.) Ska. }\end{array}$ & $\begin{array}{l}\text { Gomphonema bohemicum } \\
\text { Reichelt }\end{array}$ & $\begin{array}{l}\text { Navicula salinarum } \\
\text { var.intermedia (Grunow) } \\
\text { Cleve }\end{array}$ & $\begin{array}{l}\text { Nitzschia thermalis } \\
\text { (Ehrenberg) Auerswald }\end{array}$ \\
\hline $\begin{array}{l}\text { Cocconeis scutellum } \\
\text { Ehrenberg }\end{array}$ & $\begin{array}{l}\text { Gomphonema lanceolatum } \\
\text { Kützing }\end{array}$ & $\begin{array}{l}\text { Navicula specula } \\
\text { (Hickie) Cleve }\end{array}$ & $\begin{array}{l}\text { Opephora martyi var. } \\
\text { polymorpha Jouravleva }\end{array}$ \\
\hline $\begin{array}{l}\text { Coscinodiscus lacustris } \\
\text { Grunow }\end{array}$ & $\begin{array}{l}\text { Gomphonema montanum } \\
\text { (Schumann) Grunow }\end{array}$ & Navicula tuscula Ehrenberg & $\begin{array}{l}\text { Pleurosigma elongatum } \\
\text { W.Smith }\end{array}$ \\
\hline $\begin{array}{l}\text { Cyclotella bodanica } \\
\text { Eulenstein ex Grunow }\end{array}$ & $\begin{array}{l}\text { Gomphonema truncatum var. } \\
\text { capitatum Ehrenberg }\end{array}$ & $\begin{array}{l}\text { Navicula viridula (Kützing) } \\
\text { Ehrenberg }\end{array}$ & $\begin{array}{l}\text { Stauroneis anceps } \\
\text { Ehrenberg }\end{array}$ \\
\hline $\begin{array}{l}\text { Cyclotella glomerata } \\
\text { Bachmann }\end{array}$ & Gomphonema sp. & Navicula verecunda Hust. & $\begin{array}{l}\text { Stauroneis schroederi } \\
\text { Hustedt }\end{array}$ \\
\hline Cyclotella ocellata Pant & $\begin{array}{l}\text { Gomphonema ventricosum } \\
\text { W.Gregory }\end{array}$ & Nitzschia acicularis W. Smith & $\begin{array}{l}\text { Suriirella obtusa var. } \\
\text { splandida Ehrenberg }\end{array}$ \\
\hline $\begin{array}{l}\text { Cyclotella operculata (Ag.) } \\
\text { kutz. }\end{array}$ & $\begin{array}{l}\text { Gyrosigma acuminatum } \\
\text { (Kützing) Rabenhorst }\end{array}$ & $\begin{array}{l}\text { Nitzschia acula (Kützing) } \\
\text { Hantzsch }\end{array}$ & $\begin{array}{l}\text { Synedra actinastroides } \\
\text { Lemmermann }\end{array}$ \\
\hline $\begin{array}{l}\text { Cyclotella meneghiniana } \\
\text { kutz. }\end{array}$ & $\begin{array}{l}\text { Mastogloia elliptica var. } \\
\text { dseri Thwaites }\end{array}$ & & Syndra acus Kützing \\
\hline $\begin{array}{l}\text { Cyclotella stelligera Cleve } \\
\text { \& Grunow Heurck }\end{array}$ & $\begin{array}{l}\text { Mastogloia smithii Thwaites } \\
\text { ex W.Smith }\end{array}$ & $\begin{array}{l}\text { Nitzschia apiculata } \\
\text { (W.Gregory) Grunow }\end{array}$ & $\begin{array}{l}\text { Synedra acus var. } \\
\text { angustissima (Grunow) } \\
\text { Van Heurck }\end{array}$ \\
\hline Cyclotella sp. & Mastogloia smithii var. & Nitzschia communis & Synedra affinis Kützing \\
\hline
\end{tabular}




\begin{tabular}{|c|c|c|c|}
\hline & lacustris Grunow & Rabenhorst & \\
\hline Cyclotella striata (Kützing) & Melosira granulata (Her.) & Nitzschia epithemoides & Synedra affinis var. \\
\hline Grunow & Ralfs & Grunow & $\begin{array}{l}\text { fasciculata (Lyngbye) } \\
\text { Grunow }\end{array}$ \\
\hline Cymbella affinis Kützing & $\begin{array}{l}\text { Melosira granulata var. } \\
\text { angustissma Muller }\end{array}$ & Nitzschia fasciculata Grunow & $\begin{array}{l}\text { Synedra delicatissima } \\
\text { W.Smith }\end{array}$ \\
\hline Cymbella cistula ( & Melosira varians C. A. & Nitzschia filiformis (W.Smith) & Synedra nana F.Meister \\
\hline Hemprich) Grun & Agradh & Van Heurck & \\
\hline Cymbella delicatula & Meridion circulare (Greville) & Nitzschia fonticola Grur & Syndra ulna (Nitzsch) \\
\hline Kützing & C.Agardh & Nilzscria Jonicoia urun. & Ehr. \\
\hline Cymbella laevis Nägeli & Navicula angalica Ralfs & $\begin{array}{l}\text { Nitzschia frustulum (Kützing) } \\
\text { Grunow }\end{array}$ & $\begin{array}{l}\text { Synedra ulna var. biceps } \\
\text { (Kützing) Schönfeldt }\end{array}$ \\
\hline Cymbella microcephala & Navicula atomus (Kützing) & Nitzschia dissipata (Kutz.) & Synedra ulna var. ramesi \\
\hline Grunow in Van Heurck & $\mathrm{W}$ & Grum & (Herib.) Hust. \\
\hline $\begin{array}{l}\text { Cymbella prostrata } \\
\text { (Berkeley) Cleve }\end{array}$ & $\begin{array}{l}\text { Navicula braunii Grunow in } \\
\text { van Heurck }\end{array}$ & Nitzschia gracilis Hantz & \\
\hline $\begin{array}{l}\text { Diatoma elongata } \\
\text { (Lyngbye) C.Agardh } \\
\text { Chlorophyceae }\end{array}$ & $\begin{array}{l}\text { Navicula confervacea } \\
\text { (Kützing) Grunow }\end{array}$ & $\begin{array}{l}\text { Nitzschia hantzschiana } \\
\text { Rabenhorst }\end{array}$ & \\
\hline$\overline{\text { Actinastrum aciculare }}$ & Cosmarium ochthodes & Nephrocytium limneticum & Scenedesmus dimorphus \\
\hline Pla) & & & $(\mathrm{T}$ \\
\hline Actinastrum hantzschii & Cosmarium punctulatum & Nephrocytium lunatum $\mathrm{W}$. & Scenedesmus ecornis ( \\
\hline Lagerheim & Brébisson & West & Ehrenberg ) Chodat \\
\hline $\begin{array}{l}\text { Actinastrum hantzschii var. } \\
\text { fluviatile J.B.L.Schröder }\end{array}$ & Cosmarium sp. & Oedogonium sp. & $\begin{array}{l}\text { Scenedesmus bicudatus } \\
\text { Dedusenko }\end{array}$ \\
\hline $\begin{array}{l}\text { Actinastrum hantzschii var. } \\
\text { javanicum C.Bernard }\end{array}$ & $\begin{array}{l}\text { Crucigenia tetrapedia ( } \\
\text { Kirchner) W. \& G.S. West }\end{array}$ & Oocystis solitaria Wittrock & $\begin{array}{l}\text { Scenedesmus } \\
\text { intermedius Chodat }\end{array}$ \\
\hline $\begin{array}{l}\text { Ankistrodesmus falcatus } \\
\text { (Corda) Ralfs }\end{array}$ & Crucigenia quadrata Morren & $\begin{array}{l}\text { Oocystis marssonii } \\
\text { Lemmermann }\end{array}$ & $\begin{array}{l}\text { Scenedesmus } \\
\text { quadricauda ( Turpin ) } \\
\text { Brébisson }\end{array}$ \\
\hline $\begin{array}{l}\text { Ankistrodesmus fusiformis } \\
\text { Corda }\end{array}$ & $\begin{array}{l}\text { Dactylosphaerium jurisii } \\
\text { Hindak }\end{array}$ & Oocystis parva W.\&G.S. West & $\begin{array}{l}\text { Scenedesmus } \\
\text { protuberans Fritsch }\end{array}$ \\
\hline $\begin{array}{l}\text { Ankistrodesmus spiralis } \\
\text { (Turner) Lemmermann }\end{array}$ & $\begin{array}{l}\text { Dicloster acuatus C.-C.Jao, } \\
\text { Y.S.Wei \& H.C.Hu }\end{array}$ & Oocystis borgei Snow & $\begin{array}{l}\text { Scenedesmus } \\
\text { subspicatus Chodat }\end{array}$ \\
\hline $\begin{array}{l}\text { Ankistrodesmus convulatus } \\
\text { Corda }\end{array}$ & $\begin{array}{l}\text { Dictosphaerium } \\
\text { ehrenbergianum Nägeli }\end{array}$ & Oocystis elliptica W. West & $\begin{array}{l}\text { Scenedesmus } \\
\text { sempervirens Chodat }\end{array}$ \\
\hline $\begin{array}{l}\text { Ankistrodesmus } \\
\text { nitzschioides G.S. West }\end{array}$ & $\begin{array}{l}\text { Dictyosphaerium } \\
\text { planctonicum Tiffany \& } \\
\text { Ahlstrom }\end{array}$ & Oocystis crassa Wittrocle & $\begin{array}{l}\text { Scenedesmus spinosas } \\
\text { Chodat }\end{array}$ \\
\hline $\begin{array}{l}\text { Basicladia vivipara } \\
\text { Normandin \& Taft }\end{array}$ & $\begin{array}{l}\text { Dictosphaerium pulchellum } \\
\text { Wood }\end{array}$ & Pediastrum araneosum & $\begin{array}{l}\text { Scenedesmus bijugatus } \\
\text { ( Turp. ) Kutzing }\end{array}$ \\
\hline $\begin{array}{l}\text { Carteria globosa Korshikov } \\
\text { in Pascher }\end{array}$ & $\begin{array}{l}\text { Dictosphaerium } \\
\text { subsolitarium Van Goor }\end{array}$ & $\begin{array}{l}\text { Pediastrum clathratum } \\
\text { (Schröder) Lemmermann. }\end{array}$ & Scenedesmus sp. \\
\hline $\begin{array}{l}\text { Characium limneticum } \\
\text { Lemmermann }\end{array}$ & $\begin{array}{l}\text { Docidium baculum Brébisson } \\
\text { ex Ralfs }\end{array}$ & Pediastrum duplex Meyen & $\begin{array}{l}\text { Schroederia setigera } \\
\text { (Schröder) Lemmermann }\end{array}$ \\
\hline $\begin{array}{l}\text { Chlamydomonas globosa } \\
\text { Snow }\end{array}$ & $\begin{array}{l}\text { Eudorina unicocca } \\
\text { G.M.Smith }\end{array}$ & Pediastrum simplex Meyen & $\begin{array}{l}\text { Selenastrum bibraianum } \\
\text { Reinsch }\end{array}$ \\
\hline Chlorella vulgaris & Franceia ovalis (Francé ) & Pediastrum simplex var. & Selenastrum \\
\hline ack & Lemmermann & ramci (Reinsch ) wolle & capricornutum Printz \\
\hline Choricystis coccoides & Glot & Pediastrum tetras (Ehrenberg) & Selenastrum gracilis \\
\hline (Rodhe \& Skuja) Fott & Glo & Ralfs & Reinsch \\
\hline $\begin{array}{l}\text { Closterium accrosum } \\
\text { (Schr.) Ehr. }\end{array}$ & Golekinia radiata Chodat & $\begin{array}{l}\text { Planktonema lauterbornii } \\
\text { Schmidle }\end{array}$ & $\begin{array}{l}\text { Selenastrum minutum } \\
\text { Naegeli }\end{array}$ \\
\hline erium acutum & Keratococcus braunii & Pleurotaenium ehrenbergii & Sphaerocystis schroeteri \\
\hline Bredisson & (Nägeli) Hindák & & Chodat \\
\hline Closterium acutum var. & Keratococcus suecicus & Pleurotaenium truncatum & Spirogyra sp. \\
\hline
\end{tabular}




\begin{tabular}{|c|c|c|c|}
\hline variabile (Lem.) Willi Kre. & Hindák & (Brébisson ex Ralfs) Nägeli & \\
\hline Closterium ceratium Perty & $\begin{array}{l}\text { Kirchneriella contorta } \\
\text { (Schmidle) Bohlin }\end{array}$ & Pseudosphaerocystis lacustris & $\begin{array}{l}\text { Staurastrum paradoxum } \\
\text { Meyen ex Ralfs }\end{array}$ \\
\hline Closterium strigosum & Koliella spiculiformis & Quadrigula closterioides & Stichococcus bacillaris \\
\hline Brébisson & (Vischer) Hindák & (Bohlin) Printz & Nägeli \\
\hline Coelastrum microporum & Legerheimia ciliata. (Lag.) & hadiococcus nimbatus & Tetraedron triangulare \\
\hline Nägeli & Chodat & 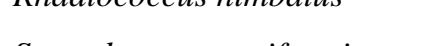 & Korshikov \\
\hline $\begin{array}{l}\text { Coelastrum reticulatum } \\
\text { (P.A.Dangeard) Senn }\end{array}$ & $\begin{array}{l}\text { Legerheimia citriformis } \\
\text { (Snow ) G.M. Smith }\end{array}$ & $\begin{array}{l}\text { Scenedesmus acutiformis } \\
\text { Schröder }\end{array}$ & $\begin{array}{l}\text { Tetraedron minimum (A. } \\
\text { Braun) Hansgirg }\end{array}$ \\
\hline $\begin{array}{l}\text { Coelastrum sphaericum } \\
\text { Nägeli }\end{array}$ & Legerheimia subsalsa Lemm. & $\begin{array}{l}\text { Scenedesmus acuminatus } \\
\text { (Lagerh. ) Chodat }\end{array}$ & $\begin{array}{l}\text { Tetradesmus } \\
\text { wisconsinensis } \\
\text { G.M.Smith }\end{array}$ \\
\hline $\begin{array}{l}\text { Coelastrum cambricum } \\
\text { Archer }\end{array}$ & $\begin{array}{l}\text { Monoraphidium dybowskii } \\
\text { (Wol. ) Hindák\& } \\
\text { Komárková-Legenerová }\end{array}$ & $\begin{array}{l}\text { Scenedesmus abundans var. } \\
\text { longicauda G.M. Smith }\end{array}$ & $\begin{array}{l}\text { Tetrallantos lagerheimii } \\
\text { Teiling }\end{array}$ \\
\hline $\begin{array}{l}\text { Cosmarium depressum } \\
\text { (Nägeli) P.Lundell }\end{array}$ & $\begin{array}{l}\text { Monoraphidium contortum } \\
\text { Thuret }\end{array}$ & $\begin{array}{l}\text { Scenedesmus denticulatus } \\
\text { Lagerheim }\end{array}$ & $\begin{array}{l}\text { Treubaria } \\
\text { triappendiculata } \\
\text { C.Bernard }\end{array}$ \\
\hline $\begin{array}{l}\text { Cosmarium formosulum var. } \\
\text { nathorstii (Boldt) West \& } \\
\text { G.S.West }\end{array}$ & $\begin{array}{l}\text { Monoraphidium griffithii } \\
\text { (Ber.) Komárková-Legnerová }\end{array}$ & $\begin{array}{l}\text { Scenedesmus obliqus ( Turpin } \\
\text { ) Küzing }\end{array}$ & Ulothrix sp. \\
\hline $\begin{array}{l}\text { Cosmarium laeve var. } \\
\text { distentum G.S.West }\end{array}$ & Mougeotia sp. & $\begin{array}{l}\text { Scenedesmus opoliensis } \\
\text { P.G.Richter }\end{array}$ & $\begin{array}{l}\text { Westella botryoides } \\
\text { (West) De Wildeman }\end{array}$ \\
\hline Cyanophyceae & $\begin{array}{l}\text { Merismopedia danubiana } \\
\text { Hortobágyi }\end{array}$ & Phormidium molle Gomont & $\underline{\text { Euglenophyceae }}$ \\
\hline Anc & & & \\
\hline Rabenhorst ex Bornet \& & Merismopedia glauca & & Euglena acus \\
\hline & (Ehrenberg) & Phormidium sp. & (O.F.Müller) Ehrenberg \\
\hline Aphanizomenon flosaquae & Merismopedia punctata & & Euglena gracilis \\
\hline Ralfs ex Bornet \& Flahault & Meyen & $\begin{array}{l}\text { Phormidium tenue Gomont } \\
\text { Planktothrix agardhii }\end{array}$ & G.A.Klebs \\
\hline Aphanocapsa elachista & Microcystis aeruginosa & (Gomont) Anagnostidis \& & Euglena pisciformis \\
\hline S.West & ing & Komárek & Klebs \\
\hline Chroococcus dispersus & ocystis flosaquae & Pseudanabaena galeata & \\
\hline (Keissler) Lemmermann & (Wittrock) Kirchner & Böcher & $\begin{array}{l}\text { Phacus caudatus Huoner } \\
\text { Phacus pleuronectes }\end{array}$ \\
\hline $\begin{array}{l}\text { Chroococcus minutus } \\
\text { (Kiitzino) Näoeli }\end{array}$ & Microcystis grevillei & Raphidiopsis curvata Fritsch & $\begin{array}{l}\text { (O.F.Müller) Nitzsch ex } \\
\text { Duiardin }\end{array}$ \\
\hline Chroococcus turgidus & Oscillatoria agardhii & Rhabdoderma irregulare & Trachelomonas \\
\hline (Kützing) Nägeli & $\begin{array}{l}\text { Gomont } \\
\text { Oscillatoria chalybea }\end{array}$ & $\begin{array}{l}\text { (Naumann) Geitler } \\
\text { Rhabdoderma lineare }\end{array}$ & planctonica Svirenko \\
\hline Cyanothece sp. & Mertens ex Gomont & Schmidle \& Lauterborn & Cryptophyceae \\
\hline Cylindrospermopsis & & Rhabdoderma lineare var. & Chromonas acuta \\
\hline raciboroskii Woloszynska & Oscillatoria curviceps & unicellulare Hollerbach & Utermohl \\
\hline Eucapsa densa M.T. de P. & & & Cryptomonas erosa \\
\hline 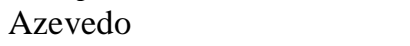 & Oscillatoria exospira Skuja & Romeria victoriae komarek & Ehrenberg \\
\hline Gomphosphaeria aponina & Oscillatoria planctonica & & Cryptomonas marssonii \\
\hline Kü & Woloszynska & Spirulina platensis & Skuja \\
\hline Gomphosphaeria fusca & Oscillatoria limnetica & & Cryptomonas rostrata \\
\hline & Lemmermann & & Triozkaja \\
\hline Leptolyngbya perelegans & Oscillatoria limosa C.Agardh & Ceratium hirundinella & Cryptomonas phaseolus \\
\hline (Lem.) Anag. \& Komá. & ex Gomont & (O.F.Müller) Dujardin & Skuja \\
\hline Lyngbya limnetica & Oscillatoria tenuis C.Agardh & & \\
\hline Lemmermann & ex Gomont & Exuviaella apora Schiller & Xanthophyceae \\
\hline $\begin{array}{l}\text { Lyngbya major Meneghinı } \\
\text { ex Gomont }\end{array}$ & Oscillatoria sp. & Gymnodinium discoidal & $\begin{array}{l}\text { Tribonema minus (Wille) } \\
\text { Hazen }\end{array}$ \\
\hline
\end{tabular}


Lyngbya martensiana Meneghini ex Gomont Lyngbya profundalis Lindstedt
Phormidium dictyothallum

Skuja

Phormidium interruptum

Kutz.

Phormidium laminosum

Gomont ex Gomont
Peridinium cinctum

O.F.Muller

Peridinium penardiforme

Lindemann

Peridinium sp.

\section{Epiphytic microinvertebrates}

Maximum occurrence of epiphytic invertebrates (20008 org./g plant dw) was recorded during winter while the lowest (18684 org./g plant dw) was observed during summer. On the other hand, the highest number of epiphytic microinvertebrate species and taxa was recorded during the summer season (23 species) while the lowest one was found during the winter season (19 species). An average of Twenty-five species and taxa were recorded belonging to Rotifera (14 species), Protozoa (4 species), Cladocera (2 species). In addition, one species of Nematoda, ostracoda, and Oligochaeta. Copepoda larvae and insect larvae were observed with low abundance.

Protozoa were the dominant group during this study, it forms $51.76 \%$ of the total epiphytic microinvertebrates and was represented by four species (Arcella discoides, Centropyxis aculeate, Euglypha sp., and Vorticella sp.) (Fig.5). Rotifers recorded the highest number of species (14) and it was represented by $28.12 \%$ of the total epiphytic microinvertebrates count. Rotifera were dominated with Philodina sp. (16.31\% of the total epiphytic microinvertebrates. Brachionus spp. were observed at the most studied stations. (Table 6). Nematoda formed $17.82 \%$ of the total epiphytic microinvertebrates with the highest biomass during winter. Cladocera was represented by 2 species; genus Alona and Diphanosoma.

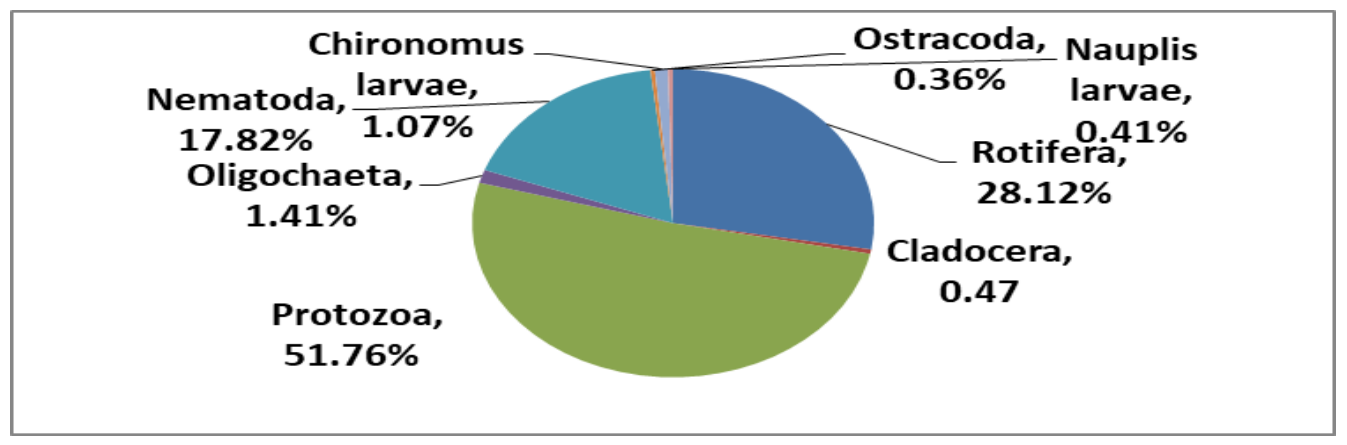

Fig.5. The percentage of each epiphytic microinvertbrates groups associated with the floating plant Eichhornia crassipes at Rosetta branch. 
Table 6. Variations of epiphytic microinvertbrates (org./g plant dw) at the Rosetta branch.

\begin{tabular}{|l|c|c|c|c|c|c|}
\hline \multirow{2}{*}{ Group/species } & \multicolumn{2}{|c|}{ winter } & \multicolumn{2}{c|}{ Summer } & \multicolumn{2}{c|}{ Average } \\
\cline { 2 - 7 } & Number & \% & Number & \% & Number & $\%$ \\
\hline Rotifera & & & & & & \\
\hline Anuraeopsis fissa & 135 & 0.67 & 45 & 0.24 & 90 & 0.46 \\
\hline Asplanchna priodonta & 0 & 0 & 104 & 0.56 & 52 & 0.28 \\
\hline Brachionus patulus & 135 & 0.68 & 193 & 1.03 & 164 & 0.86 \\
\hline Brachionus plicatilis & 418 & 2.09 & 904 & 4.84 & 661 & 3.46 \\
\hline Brachionus qudridentatus & 556 & 2.78 & 389 & 2.08 & 472 & 2.43 \\
\hline Colurella adriatica & 30 & 0.15 & 26 & 0.14 & 28 & 0.14 \\
\hline Euchlanis dilatata & 115 & 0.57 & 292 & 1.56 & 203 & 1.07 \\
\hline Keratella cochlearis & 0 & 0 & 92 & 0.49 & 46 & 0.25 \\
\hline Keratella tropica & 73 & 0.37 & 0 & 0 & 37 & 0.18 \\
\hline Monostyla bulla & 267 & 1.33 & 172 & 0.92 & 219 & 1.13 \\
\hline Monostyla Closterocerca & 358 & 1.79 & 75 & 0.4 & 216 & 1.1 \\
\hline Philodina sp. & 1439 & 7.19 & 4753 & 25.44 & 3096 & 16.31 \\
\hline Filinia longiseta & 0 & 0 & 126 & 0.67 & 63 & 0.34 \\
\hline Trichocerca sp. & 0 & 0 & 92 & 0.49 & 46 & 0.25 \\
\hline Total Rotifera & 3525 & 17.62 & 7218 & 38.63 & 5371 & 28.12 \\
\hline Cladocera & & & & & & \\
\hline Alona intermedia & 82 & 0.41 & 0 & 0 & 41 & 0.2 \\
\hline Diphanosoma excisum & 54 & 0.27 & 49 & 0.26 & 52 & 0.27 \\
\hline Protozoa & & & & & & \\
\hline Arcella discoides & 531 & 2.66 & 289 & 1.55 & 410 & 2.1 \\
\hline Centropyxis aculeata & 56 & 0.28 & 77 & 0.41 & 66 & 0.34 \\
\hline Euglypha sp. & 157 & 0.79 & 110 & 0.59 & 133 & 0.69 \\
\hline Vorticella sp. & 9084 & 45.4 & 9697 & 51.9 & 9390 & 48.65 \\
\hline Total Protozoa & 9821 & 49.08 & 10173 & 54.44 & 9997 & 51.76 \\
\hline Oligochaeta & 342 & 1.71 & 208 & 1.12 & 275 & 1.41 \\
\hline Nematoda & 6166 & 30.82 & 901 & 4.82 & 3534 & 17.82 \\
\hline Ostracoda & 0 & 0 & 135 & 0.72 & 68 & 0.36 \\
\hline Chironomus larvae & 0 & 0 & 400 & 2.14 & 200 & 1.07 \\
\hline Nauplis larvae & 19 & 0.09 & 135 & 0.72 & 77 & 0.41 \\
\hline Total number & 20008 & 100 & 18684 & 100 & 19346 & 100 \\
\hline Species/Taxa & 19 & & 23 & & 25 & \\
\hline
\end{tabular}

\section{Documentation and evaluation of zooplankton}

According to the results, the winter recorded thirty-eight taxa of zooplankton included in five groups, Rotifera (28 taxa), Copepoda (2 taxa), Cladocera (3 taxa), Meroplankton (2 taxa), and Protozoa (3 taxa), while the summer recorded forty-five taxa of zooplankton, included in five groups, Rotifera (29 taxa), Copepoda (3 taxa), Cladocera (6 taxa), Meroplankton (4 taxa) and Protozoa (3 taxa) were identified based on morphological characters. The highest number of Rotifera species during winter and summer were calculated in R7 (638400 org. $\mathrm{m}^{-3}$ ) and (600000 org. $\mathrm{m}^{-3}$ ) respectively. Numbers of Copepoda were observed at R2, R3, and R5 during winter and RC, R2, and $\mathrm{R} 3$ during summer. A total of $12000 \mathrm{org} . \mathrm{m}^{-3}$ and $62400 \mathrm{org} . \mathrm{m}^{-3}$ of Copepoda species were recorded in $\mathrm{R} 7$ during winter and summer respectively (Table 7). 
Table 7:Standing crop of zooplankton species $\left(\right.$ org. $\mathrm{m}^{-3}$ ) at the Rosetta branch

\begin{tabular}{|c|c|c|c|c|c|c|c|c|c|c|c|c|}
\hline \multirow{2}{*}{$\begin{array}{c}\text { Sampl } \\
\mathrm{e}\end{array}$} & Rotifera & $\begin{array}{c}\text { Copepod } \\
\mathrm{a}\end{array}$ & $\begin{array}{c}\text { Cladocer } \\
\mathrm{a}\end{array}$ & $\begin{array}{c}\text { Meroplank } \\
\text { ton }\end{array}$ & $\begin{array}{c}\text { Prortozo } \\
\mathrm{a}\end{array}$ & $\begin{array}{c}\text { Total } \\
\text { zooplan } \\
\text { kton }\end{array}$ & Rotifera & Copepoda & $\begin{array}{c}\text { Cladocer } \\
\mathrm{a}\end{array}$ & $\begin{array}{c}\text { Meroplankt } \\
\mathrm{n}\end{array}$ & $\begin{array}{c}\text { Prortoz } \\
\text { oa }\end{array}$ & $\begin{array}{c}\text { Total } \\
\text { zooplankton }\end{array}$ \\
\hline RC & 110400 & 2400 & 0 & 2400 & 4800 & 120000 & 160800 & 0 & 2400 & 0 & 0 & 163200 \\
\hline R1 & 96000 & 2400 & 0 & 4800 & 2400 & 105600 & 187200 & 7200 & 2400 & 21600 & 0 & 218400 \\
\hline R2 & 117600 & 0 & 2400 & 12000 & 2400 & 134400 & 96000 & 0 & 2400 & 12000 & 24000 & 134400 \\
\hline R3 & 72000 & 0 & 2400 & 2400 & 12000 & 88800 & 110400 & 0 & 4800 & 9600 & 14400 & 139200 \\
\hline R4 & 36000 & 7200 & 0 & 0 & 21600 & 64800 & 451200 & 28800 & 0 & 0 & 0 & 480000 \\
\hline R5 & 60000 & 0 & 0 & 0 & 2400 & 62400 & 381600 & 2400 & 0 & 4800 & 0 & 388800 \\
\hline R6 & 103200 & 2400 & 0 & 2400 & 67200 & 175200 & 595200 & 31200 & 43200 & 2400 & 0 & 672000 \\
\hline R7 & 638400 & 12000 & 2400 & 7200 & 7200 & 667200 & 600000 & 62400 & 26400 & 4800 & 0 & 693600 \\
\hline
\end{tabular}

A

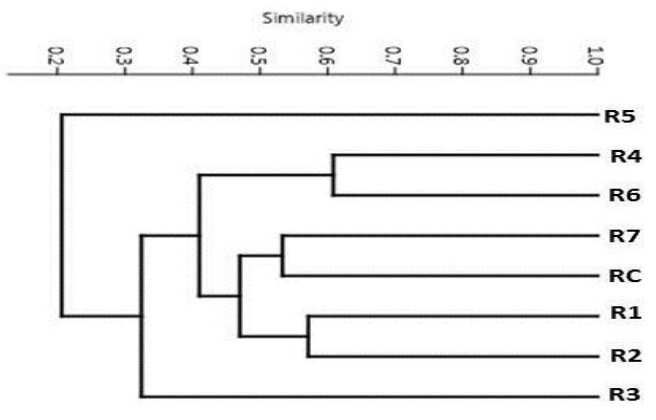

B

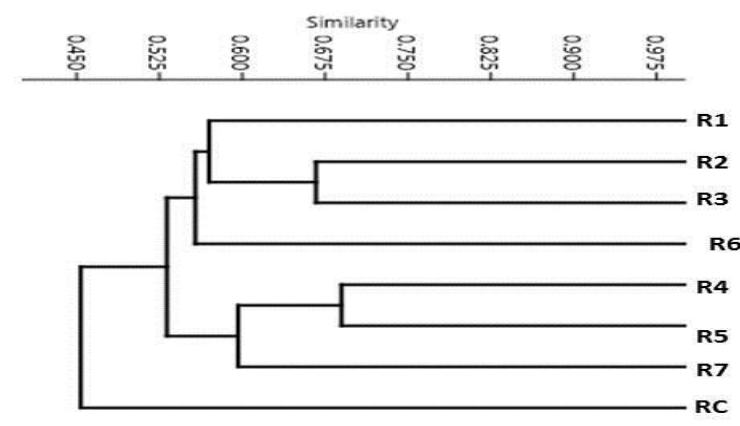

Fig.6.Clustering analysis based on zooplankton biodiversity. A) winter, B) summer.

During Winter, a total of 2400 org. $\mathrm{m}^{-3}$ of Cladocera were recorded at R2, R3, and R7 stations. The Meroplankton organisms were presented by Nematoda species (in R1, $\mathrm{R} 2, \mathrm{R} 3$, and R6) and Oligochaeta larvae (in RC and R7), while summer recorded a total of 43200 org. $\mathrm{m}^{-3}$ Cladocera at R6 station. No Cladocera species was observed in both R4 and R5. The Meroplankton organisms were presented by Nematoda species (in R1, R2, and R6), Chironomus larvae (in R3, R5, and R7), Chironomus pupa (in R5) and Oligochaeta larvae (R1). Three Protozoa species were detected at the two seasons. These species were represented by Arcella spp., Colony of Zoothamnium duplicatum, and Pseudodileptus species.

\section{Clustering analysis}

Data mentioned in Fig. (6) shows the winter was recorded high similarity values between each of the following stations: (R1 and R2), (RC and R7) and (R4 and R6). The station (R5) is distantly related to the stations ( $R C, R 1, R 2, R 3$, and R4). The similarity between the stations (R5 and R6) is higher than the similarity between both (R5 \& R7). The highest similarity value was noted between the R1 and R2 stations, while during the summer recorded high similarity values between each of the following station pairs: (R1and R2), (R2 and R3), (R4 and R5) and (R4 and R7). The station (RC) is distantly related to all the other evaluated stations. The similarity between the stations (R6) and each of R1, R2, and R3 is similar. The lowest similarity value was noted between the R4, and RC. 


\section{The zooplankton species richness, evenness, and diversity index}

The total zooplankton species (S) species richness (d), evenness (J), and diversity index $(\mathrm{H})$ in each the evaluated Rosetta branch station were calculated in each estimated season (Table 8). The calculated values were varied among evaluated stations within each estimated season. Concerning the seasonal variations, the highest $\mathrm{S}, \mathrm{d}, \mathrm{J}$, and $\mathrm{H}$ values were detected in the summer within the most evaluated stations (RC, R1, R3, R4, R5, and R7). On the other hand, this observation was reversed in the station (R2). Regarding station R6, (d) and $(\mathrm{H})$ values in summer were higher than those calculated in winter.

Table 8: Total zooplankton species, species richness, evenness and diversity index

\begin{tabular}{|c|c|c|c|c|c|c|c|c|}
\hline \multirow[t]{2}{*}{ Stations } & \multicolumn{4}{|c|}{ Winter } & \multicolumn{4}{|c|}{ Summer } \\
\hline & $\mathbf{S}$ & $d$ & $\mathbf{J}$ & $\mathbf{H}$ & $\mathbf{S}$ & d & $\mathbf{J}$ & $\mathbf{H}$ \\
\hline $\mathbf{R C}$ & 12 & 0.94 & 0.71 & 1.78 & 15 & 1.17 & 0.8 & 2.16 \\
\hline R1 & 11 & 0.86 & 0.76 & 1.83 & 13 & 0.98 & 0.78 & 1.99 \\
\hline $\mathbf{R 2}$ & 16 & 1.27 & 0.91 & 2.53 & 12 & 0.93 & 0.88 & 2.18 \\
\hline $\mathbf{R 3}$ & 13 & 1.05 & 0.89 & 2.29 & 15 & 1.18 & 0.93 & 2.51 \\
\hline R4 & 6 & 0.45 & 0.87 & 1.57 & 15 & 1.07 & 0.6 & 1.63 \\
\hline$\overline{\mathrm{R} 5}$ & 4 & 0.27 & 0.42 & 0.59 & 15 & 1.01 & 0.71 & 1.88 \\
\hline$\overline{\mathrm{R} 6}$ & 15 & 1.16 & 0.74 & 2 & 14 & 1.34 & 0.72 & 2.12 \\
\hline R7 & 16 & 1.11 & 0.72 & 2.01 & 19 & 1.33 & 0.82 & 2.41 \\
\hline
\end{tabular}

$\mathrm{S}=$ Total species, $\mathrm{d}=$ =species richness and $\mathrm{J}=$ evenness, $\mathrm{R}=$ station, $\mathrm{H}=$ diversity index.

A total of five zooplankton groups (Rotifera, Copepoda, Cladocera, Meroplankton, and Protozoa) were documented and identified based on morphological characters. Rotifera (constitute 28 taxa in winter and 29 taxa in summer). The standing crop values of the Rotifera group were varied among the evaluated stations. Copepoda species was represented by Acanthocyclops americanus and Nauplius larva in the winter. In addition, the third species (Mesocyclops leuckarti) was recorded only in summer (station R7).

The Cladocera and Meroplankton organisms were documented in some stations, while the Protozoa group were detected (dominated) in all stations in winter. The highest Protozoa species was recorded in the station (R6). On the other hand, this group was documented only in two stations (R2 and R3) in the summer. Regarding the calculated diversity index $(\mathrm{H})$, all $(\mathrm{H})$ values did not match 3. It ranged at the winter from 0.59 (R5) to 2.53 (R2). Concerning the summer, these values ranged from 1.63 (R4) to 2.51 (R3).

\section{Bacteriology}

Total bacterial counts are shown in Table 9. Numbers at $22^{\circ} \mathrm{C}$ ranged between $1 \times 10^{4}$ and $800 \times 10^{4} \mathrm{CFU} / \mathrm{ml}$, while at $37^{\circ} \mathrm{C}$ ranged from $3 \times 10^{4}$ to $840 \times 10^{4} \mathrm{CFU} / \mathrm{ml}$, the highest values (at $22^{\circ} \mathrm{C}$ and $37^{\circ} \mathrm{C}$ ) recorded during summer at R1 (El-Rahawy drain outfall), affected by El-Rahawy drain. 
Table 9: Variation of Total viable bacterial count (CFU/ml) at the Rosetta branch

\begin{tabular}{|c|c|c|c|c|}
\hline \multirow{2}{*}{ Stations } & \multicolumn{2}{|c|}{ Winter } & \multicolumn{2}{c|}{ Summer } \\
\cline { 2 - 5 } & TVBC at $37^{\circ} \mathrm{C}$ & TVBC at $22^{\circ} \mathrm{C}$ & TVBC at $37^{\circ} \mathrm{C}$ & TVBC at $22^{\circ} \mathrm{C}$ \\
\hline RC & $3 \times 10^{4}$ & $1 \times 10^{4}$ & $12 \times 10^{4}$ & $9 \times 10^{4}$ \\
\hline R1 & $145 \times 10^{4}$ & $98 \times 10^{4}$ & $840 \times 10^{4}$ & $800 \times 10^{4}$ \\
\hline R2 & $93 \times 10^{4}$ & $65 \times 10^{4}$ & $460 \times 10^{4}$ & $380 \times 10^{4}$ \\
\hline R3 & $84 \times 10^{4}$ & $80 \times 10^{4}$ & $125 \times 10^{4}$ & $88 \times 10^{4}$ \\
\hline R4 & $50 \times 10^{4}$ & $12 \times 10^{4}$ & $108 \times 10^{4}$ & $85 \times 10^{4}$ \\
\hline R5 & $30 \times 10^{4}$ & $26 \times 10^{4}$ & $98 \times 10^{4}$ & $78 \times 10^{4}$ \\
\hline R6 & $69 \times 10^{4}$ & $32 \times 10^{4}$ & $220 \times 10^{4}$ & $185 \times 10^{4}$ \\
\hline R7 & $102 \times 10^{4}$ & $85 \times 10^{4}$ & $334 \times 10^{4}$ & $346 \times 10^{4}$ \\
\hline Mean & $72 \times 10^{4}$ & $49.9 \times 10^{4}$ & $274.6 \times 10^{4}$ & $246.4 \times 10^{4}$ \\
\hline Max & $145 \times 10^{4}$ & $98 \times 10^{4}$ & $840 \times 10^{4}$ & $800 \times 10^{4}$ \\
\hline Min & $3 \times 10^{4}$ & $1 \times 10^{4}$ & $12 \times 10^{4}$ & $9 \times 10^{4}$ \\
\hline SD & $44.5 \times 10^{4}$ & $36.6 \times 10^{4}$ & $270.1 \times 10^{4}$ & $260.2 \times 10^{4}$ \\
\hline
\end{tabular}

$\mathrm{Max}=$ maximum, Min=minimum, $\mathrm{SD}=$ standard deviation.

Table 10: Enumeration of TC, FC, FS, E. coli, S.aureus and P.aeruginosa at the Rosetta branch.

\begin{tabular}{|c|c|c|c|c|c|c|c|c|c|c|c|c|}
\hline \multirow[b]{2}{*}{$\begin{array}{c}\text { Stati } \\
\text { ons }\end{array}$} & \multicolumn{6}{|c|}{ Winter } & \multicolumn{6}{|c|}{ Summer } \\
\hline & $\begin{array}{c}\mathrm{TC} \times 10^{3} \\
\mathrm{MPN} / 10 \\
0 \mathrm{ml}\end{array}$ & $\begin{array}{l}\mathrm{FC} \times 10^{3} \\
\mathrm{MPN} / 10 \\
0 \mathrm{ml}\end{array}$ & $\begin{array}{l}\mathrm{FS} \times 10^{3} \\
\mathrm{MPN} / 10 \\
0 \mathrm{ml}\end{array}$ & $\begin{array}{c}E . \text { coli } \times \\
10^{2} \\
\text { CFU/10 } \\
0 \mathrm{ml}\end{array}$ & $\begin{array}{c}\text { S.aureu } \\
s \times 10^{2} \\
\text { CFU/10 } \\
0 \mathrm{ml}\end{array}$ & $\begin{array}{c}\text { P.aerugi } \\
\text { nosa } \\
\times 10^{2} \\
\text { MPN/10 } \\
\text { 0ml }\end{array}$ & $\begin{array}{l}\mathrm{FC} \times 10^{3} \\
\mathrm{MPN} / 10 \\
0 \mathrm{ml}\end{array}$ & $\begin{array}{l}\mathrm{FS} \times 10^{3} \\
\mathrm{MPN} / 10 \\
0 \mathrm{ml}\end{array}$ & $\begin{array}{c}\text { FS } \\
\times 10^{3} \\
\text { MPN/10 } \\
\text { 0ml }\end{array}$ & $\begin{array}{c}\text { E. coli } \times \\
10^{2} \\
\text { CFU/10 } \\
0 \mathrm{ml}\end{array}$ & $\begin{array}{c}\text { S.aureu } \\
s \times 10^{2} \\
\text { CFU/10 } \\
0 \mathrm{ml}\end{array}$ & $\begin{array}{c}\text { P.aerugi } \\
\text { nosa } \\
\times 10^{2} \\
\text { MPN/10 } \\
0 \mathrm{ml}\end{array}$ \\
\hline RC & 0.3 & 0.3 & 0.9 & N.D & 60 & N.D & 11 & 2.3 & 7 & 20 & 32 & 95 \\
\hline R1 & 46 & 15 & 110 & 130 & 155 & 1100 & 110 & 110 & 64 & 902 & 350 & 1100 \\
\hline $\mathbf{R 2}$ & 24 & 9.3 & 110 & 53 & 98 & 1100 & 110 & 110 & 110 & 260 & 88 & 1100 \\
\hline R3 & 2.3 & 2.3 & 110 & 18 & 24 & 23 & 64 & 64 & 110 & 35 & 48 & 1100 \\
\hline R4 & 7.5 & 4.3 & 110 & 36 & 165 & 290 & 23 & 23 & 110 & 14 & 178 & 290 \\
\hline R5 & 46 & 24 & 15 & 135 & 71 & 75 & 110 & 110 & 21 & 400 & 200 & 460 \\
\hline R6 & 0.9 & 0.9 & 110 & 5 & 105 & 120 & 64 & 15 & 110 & 105 & 89 & 460 \\
\hline R7 & 2.9 & 2 & 110 & 6 & 128 & 23 & 6.4 & 3.5 & 110 & 33 & 650 & 1100 \\
\hline $\begin{array}{c}\text { Mea } \\
\text { n }\end{array}$ & 16.2 & 7.3 & 84.5 & 54.7 & 100.8 & 390.1 & 62.3 & 54.7 & 80.3 & 221.1 & 204.4 & 713.1 \\
\hline Max & 46 & 24 & 110 & 135 & 165 & 1100 & 110 & 110 & 110 & 902 & 650 & 1100 \\
\hline Min & 0.3 & 0.3 & 0.9 & 5 & 24 & 23 & 6.4 & 2.3 & 7 & 14 & 32 & 95 \\
\hline SD & 19.9 & 8.4 & 47.4 & 55.1 & 48.2 & 477.0 & 44.9 & 49.6 & 44.0 & 308.0 & 207.5 & 428.9 \\
\hline
\end{tabular}

$\mathrm{Max}=$ maximum, Min=minimum, N.D= Not Detected, $\mathrm{SD}=$ standard deviation.

Numbers of TC \& FC and FS were mention in the Table (10), TC, FC, and FS during the winter in the range of $0.3 \times 10^{3}-46 \times 10^{3}, 0.3 \times 10^{3}-15 \times 10^{3}, 0.9 \times 10^{3}-110 \times 10^{3}$ MPN/ per $100 \mathrm{ml}$ respectively, the highest numbers were recorded at site R1, while during the summer in the range of $6.4 \times 10^{3}-110 \times 10^{3}, 2.3 \times 10^{3}-110 \times 10^{3}, 7 \times 10^{3}-110 \times 10^{3} \mathrm{MPN} /$ per $100 \mathrm{ml}$ respectively. Some pathogenic bacteria isolated from the Rosetta branch, and numbers of E. coli, $S$. aureus, and $P$. aeruginosa during the winter ranged from 0 $135 \times 10^{2}, 24 \times 10^{2}-165 \times 10^{2}, 0-1100 \times 10^{2} \mathrm{CFU} / 100 \mathrm{ml}$ respectively, but during the summer ranged from $14 \times 10^{2}-902 \times 10^{2}, 32 \times 10^{2}-650 \times 10^{2}, 95 \times 10^{2}-1100 \times 10^{2}$ $\mathrm{CFU} / 100 \mathrm{ml}$ respectively. Qualitative detection (presence-absence test) for Salmonella sp., Shigella sp. and V. cholera at Rosetta branch was listed at Table 11. 
Table11: Detection of Salmonella sp., Shigella sp. and Vibrio cholera at the Rosetta branch.

\begin{tabular}{|c|c|c|c|c|c|c|}
\hline \multirow{2}{*}{ Stations } & \multicolumn{3}{|c|}{ Winter } & \multicolumn{3}{c|}{ Summer } \\
\cline { 2 - 7 } & Salmonella sp. & Shigella sp. & Vibrio cholera & Salmonella sp. & Shigella sp. & Vibrio cholera \\
\hline RC & N.D & D & N.D & D & N.D & N.D \\
\hline R1 & D & D & D & D & D & D \\
\hline R2 & D & D & D & D & D & D \\
\hline R3 & D & D & D & D & D & D \\
\hline R4 & D & D & D & D & D & D \\
\hline R5 & D & D & D & D & D & D \\
\hline R6 & N.D & D & D & D & D & D \\
\hline R7 & N.D & D & N.D & D & D & D \\
\hline
\end{tabular}

N.D $=$ Not Detected $\quad \mathrm{D}=$ Detected

\section{Physico-chemical Characteristics}

During the present study at the Rosetta branch, water temperature was ranged between $17.7^{\circ} \mathrm{C}-20.9^{\circ} \mathrm{C}$ during the winter and incresed during the summer and was ranged from $28^{\circ} \mathrm{C}$ to $31.2{ }^{\circ} \mathrm{C}$, the highest value recorded at $\mathrm{R} 5$. Transparency values ranged from $10 \mathrm{~cm}$ to $130 \mathrm{~cm}$ during the winter while the summer ranged from $38 \mathrm{~cm}$ to $80 \mathrm{~cm}$, the minimum value was found at site R1 during winter, electrical conductivity (EC) fluctuated between $(546-1508 \mu \mathrm{S} / \mathrm{cm})$ during the winter, while EC during the summer fluctuated between $(594-1100 \mu \mathrm{S} / \mathrm{cm})$. the maximum values of EC were found at site R1 during two season. Hydrogen ion concentration $(\mathrm{pH})$ was ranged durng winter and summer between $(7.4-8.2)$ and $(7.3-8.5)$ respectively.

\section{DISCUSSION}

A total of 35 of macrophytes species were identified in the River Nile recorded by Zahran and Willis (1992). El-Amier et al., (2015) detected 70 species in the Damietta branch. Haroon and Hussian (2017) recorded 11 species in El Rayah Al- Behery and Haroon (2020b) recorded 12 species in El-Rayah Al-Nasery and El-Noubaria Canal. During the study period only seven macrophytes species were recorded, indicating low species diversity in this area. Regarding the biomass production values, the lowest values were detected for submerged macrophytes which may be related to the effect of shading caused by tall and crowded plants like, Echinochloa stagnina and Eichhornia crassipes. Comparing with the previously recorded results, the values registered for emergent and floating species were higher than those recorded by Shaltout et al., 2009. However, the data of submerged macrophytes species were relatively lower than that detected by Hussian and Haroon (2019) during the cold season for M. spicatum $\left(66.00 \mathrm{~kg} / \mathrm{m}^{2} \mathrm{ww}\right)$ and $C$. demersum $18.85 \mathrm{~kg} / \mathrm{m}^{2}$ ww from River Nile Egypt. The lower values were detected by Shaltout et al., 2016; El-Sheekh, et al., 2018 for Ceratophyllum demersum ( 0.036 to $\left.1.094 \mathrm{~kg} / \mathrm{m}^{2} \mathrm{ww}\right)$ from different locations of the Nile delta which may be related to the effect of environmental factors and allelopathic interaction between different species. 
Bacillariophyceae had the highest number of species compared with other groups of attached algae these results were shown by many authors (Adam et al., 2017, Hussian and Haroon, 2019; Haroon et al., 2020). The percentage of epiphyte algae were varied according to locations and seasons, due to concentrations of nutrients, macrophytes substances, and pollution (Wetzel, 1993). The differentiation in epiphytic microalgal species percentage may be due to plant growth period, and physicochemical characteristics (Dere et al., 2002). Jan (1996) suggested that diatoms are favored over other groups due to their size and their resistance to fluctuation in some abiotic variables (as light and temperature). Diatoms species identified in the present study are agreed with Abd El-Karim et al., (2016). Epiphytic algae are considered essentially facultative. Also, it was not influenced with the host (Wahl and Mark, 1999). On the other hand, some of them are known as specific and obligate on certain hosts (Pearson and Evans, 1990). Ondrusek (1991) found that diatoms have an advantage over another group of epiphytes due to its high fucoxanthin content. (Totti et al., 2009) stated that pennate diatoms attaching themselves to macrophytes gelatinous pads such Synedra or by the attachment of the cell along its entire valve face such as Navicula, while the centric forms as Cyclotella, held in the tangle of attached forms. (Cattaneo et al., 2004) confirmed that diatom can be an excellent specific indicator of metal contamination. (Albay and Akçaalan, 2003) mention that the species of Leptolyngbya perelegans, Lyngbya limnetica, Microcystis aeruginosa, and Phormidium sp. have a wide range of tolerance to physical disturbance (including the fluctuation of water level and large amounts of suspended solids).

El-Enany (2009) Epiphytic microinvertebrates were constituted from seven main groups at Nasser Lake; (Nematoda, Rotifera, Protozoa, Cladocera, Insecta, Oligochacta, and Copepoda). Forty-five species were recorded (27 Rotifera, 9 Cladocera, 5 Protozoa, 2 Copepoda, and 2 Oligochaeta). The wide difference in diversity between the previous study and the present was attributed to the effect of the heavy load of pollution discharged to the Rosetta branch of the Nile especially at El-Rahawy region. Mola et al. (2018) reported the epiphytic microinvertebrates were represented by 34 species and 5 larval stages involved in 8 main groups and those are lower than this study, this may be attributed to the differences in sampling methods and sampling area. Arora and Mehra (2003) investigated the species variety of planktonic and epiphytic rotifers in the backwaters of the Delhi segment of the Yamuna River (India). They recorded a total of 110 species belonging to 39 genera of 20 eutrophic families.Similar observations of Protozoa species in the present study were mentioned by Mola et al. (2018). This highest number of epiphytic Rotifera was observed by Sakuma et al. (2002); Arora and Mehra (2003) This may be attributed to the Rotifer species preferred plants which could be predominant body features, e.g. small size and short toes (sessile), to avoid predators and to feed on epiphytic algae (Ali et al., 2007). Brachionus spp. were observed at the most studied stations. This is agreed with Mola et al. (2018). Also, Ali et al. (2007) observed a 
high number of genus Lecane. Sakuma et al. (2002) stated that a large number of Lecane remained on the plant even after shaking 50 times macrophytes. This indicates that, this Rotifer was very strongly attached to submerged macrophytes. The relative abundance and composition of microinvertebrate varied depending on the type of microhabitat (e.g. plant species, benthic sediments, or water column) as mentioned by Difonzo and Campbell (1988). Similar observations of the highest biomass of Nematoda during winter were recorded at Lake Naser (El-Enany, 2009). While Mola et al. (2018) stated that Nematoda, Cladocera, Insecta (Chironomus larvae), Copepoda, and Cercaria (infected stage of Schistosoma sp.) considered the lowest recorded groups of the epiphytic microinvertbrates. The presence of Cladocera attributes to this species and can adapt to live near the bottom or on the aquatic plants Mola et al. (2018). This agreed with Iskaros et al. (2008). Cladocera is one of the most preferred species recorded in fish guts (El-Enany, 2009). The different food components generally occurred in varying decreases during different periods of the year (Azim, 1991). Also, it constitutes the basis for the development of a successful fisheries management program in fish capture and culture (Oso et al., 2006).

Zooplankton are affected by several factors such as the geological history of the area, the abundance of organisms (to be easily transported), and Physico-chemical and biological conditions in their new habitat (Shurin, 2000). Rotifers were constituted the main dominant zooplankton groups and This abundance may be due to its evolutionary adaptation ability in different environmental conditions such as salinity as confirmed by ( Mageed, 2005). The relatively low and/or disappearance zooplankton density as Copepoda (winter season) in some stations (R2, R3, and R5) and in the summer season in the station ( $\mathrm{RC}, \mathrm{R} 2$, and $\mathrm{R} 3$ ) may be due to changes in the abiotic factors (temperature, and $\mathrm{pH}$ ) and food availability. A similar observation was described by Benítez-Díaz et al. (2014) they found that, transparency, temperature, $\mathrm{pH}$, water exchanges rates, and food availability (such as $\mathrm{Chl} \mathrm{a,} \mathrm{b,} \mathrm{and} \mathrm{c)} \mathrm{were} \mathrm{the} \mathrm{main} \mathrm{factors} \mathrm{of} \mathrm{zooplankton}$ abundance (in the brackish lagoon located in Veracruz, Mexico) and diversity, elucidation the seasonal variations. During the winter, Cladocera was calculated in each R2, R3, and R7 station while this group was observed in both R4 and R5 in the second season. This rarely abundance may be due to the negative impact of light conditions on Cladocera (Benítez-Díaz et al., 2014). Also, Leech et al. (2005) found that cladocerans (Daphnia spp.) were shown to be less UV-tolerant than rotifers or copepods nevertheless of the UVR transparency of their source lake. Also, the Cladocera are sensitive to visual predation as confirmed by Ramcharan et al. (2009). The present study approved that, the (H) value in the station (R5) less than (1) indicates instability or heavy pollution while values exceeding (3) indicate stability or clean water as reported by Shannon and Weaver (1963); Mageed (2005). Total bacterial count at two different temperatures at $22^{\circ} \mathrm{C}$ and $37^{\circ} \mathrm{C}$ were considered parameters are usually used to determining water quality and bacterial density of water (Afify et al., 2019) and results of TVBCs at the rosetta 
branch are similar to those reported by Safaa et al. (2012). The highest values of TVBCs at $22^{\circ} \mathrm{C}$ and $37^{\circ} \mathrm{C}$ were recorded during summer. This might be due to high temperatures prevailing during summer. This result was in accordance with (Sabae and Saleh, 2007; El-Fadaly et al., 2001).

The minimum counts of bacterial indicators were detected at the warmer seasons (Hany and Shawky, 2011) which might be due to rapid die-off with raising solar radiation and high temperature. High results of TC densities in the present study might be attributed to the effect of the drains and human activities and pollution effect on bacterial association (Noble et al., 2004). Cabelli (1978) recommended a maximum count of TC in surface water that is going to be used as a drinking water supply was 1000 CFU/100ml. FC is used as good indicator of fecal contamination; these high values of FC might be attributed to the effect of wastewater. So that, the root of pollution at the Rosetta branch was the drains that discharge the drainage water (wastewater, agriculture waste), these findings agreed with those previously reported by (Safaa $\boldsymbol{e t}$ al., 2012). Restricted limits for surface water intended for use as drinking water supply (200 CFU/100ml) indicate unsafe water from a bacteriological point of view Cabelli (1978). Also, Afify et al. (2019) reported that the drainage water loaded with wastewater and agriculture waste causes highly ratio of pollution with fecal coliform bacteria.FS numbers effected by drainage water loaded with agricultural or industrial wastes, so that affects the cultural condition necessary for bacterial growth as $\mathrm{pH}$ and temperature. Briefly, numbers of TC, FC, and FS at the present study showed a marked increase in indicator bacteria during the warm season at the Rosetta branch as mention in the previous results reported by (Safaa et al., 2012). There are numbers of drains were discharging wastewater and agricultural waste at the Rosetta branch such as El-Rahawy drain which is highly affected at the Rosetta branch, so that, the high load of organic matter and pollutants came to the Rosetta branch (Nile River) water from El-Rahawy drain and others caused the high value of the count of microbial flora and the drainage effluents induced the active multiplication of the bacteria, these results in accordance with Safaa $\boldsymbol{e t}$ al. (2012). The municipal and agricultural sewage wastes discharged into the water body cause a serious problem of its water quality (Afify et al., 2019). E.coli is the best biological water indicator for public health protection because it is present in extremely high numbers in the feces of all mammals (Edberg et al., 2000). Saad et al. (2012) found that E. coli was detected in all samples collected from River Nile water at Great Cairo, Egypt. Yehia and Sabae (2011) reported that the MPN count of $P$. aeruginosa ranged from 0 to $4600 / 100 \mathrm{~mL}$ at ElSalam canal. Also, El-Bahnasawy (2013), isolated $P$. aeruginosa from water samples of the Rosetta branch. Bacterial diseases are commonly associated with fecal contamination of water. Ex. Salmonella (Typhoid, paratyphoid,), Shigella (Bacterial dysentery), V. cholerae (Cholera). The water-borne disease remains a major public health problem in many countries this is where a pathogen is transmitted by ingestion of contaminated 
water. Numbers of TC and FC and pathogens at the Rosetta branch during the current study are not in match with the Egyptian standards (2007) for drinking water quality.

Relationship between macrophytes, microinvertebrates, microalgea, zooplankton, bacteria, and water characteristics

Principal component analysis (PCA) shows different relations between different biological aspects and physicochemical parameters of water (Fig.7). There are some biological parameters closely correlated with others such as TVBC at $22^{\circ} \mathrm{C}$ were significantly strong correlated with $\mathrm{TVBC}$ at $37^{\circ} \mathrm{C}, \mathrm{TC}, \mathrm{FC}$, Meroplankton, Cyanophyceae, and Dinophyceae ( $\mathrm{r}=0.99,0.62,0.64,0.81,0.59$ and 0.52 respectively).

Rotifera was more associated with Copepoda, Chlorophyceae and Polygonum tomentosum ( $\mathrm{r}=0.76,0.69$ and 0.12 respectively). Also Cladocera were significantly correlated with FS, Oligochaeta, Cryptophyceae. Cyperus alopecuroides and Polygonum tomentosum ( $\mathrm{r}=0.50,0.51,0.85,0.37$ and 0.34 respectively).The correlation statistical analysis shows a significant positive relation between Nematoda and Ceratophyllum demersum, Eichhornia crassipes ( $\mathrm{r}=0.88$, and 0.41 respectively). On the other hand, there is a strong positive correlation between biological Aspects and physicochemical parameters such as Total Dissolved Solid show a significant relation with Ceratophyllum demersum, Eichhornia crassipes and Nematoda ( $\mathrm{r}=0.64,0.55$ and 0.67 respectively).

Temperature had a strong positive correlation with TC, FC, and Euglenophyceae with a significance level alpha more than 0.05. Orthophosphorus is a strong positive correlation with $\mathrm{TVBC}$ at $37^{\circ} \mathrm{C}$, TVBC at $22^{\circ} \mathrm{C}$, Meroplankton, Cyanophyceae, Dinophyceae and Cryptophyceae with a significance level alpha of more than 0.05 and weak correlation with P. tom Polygonum tomentosum, Ceratophyllum demersum, Eichhornia crassipes, Xanthophyceae, Nematoda, Total zooplankton, Vorticella sp., Total Protozoa, Cladocera,TC, FC, FS and Protozoa with a significance level alpha lower than 0.05, also there are negative correlation between Rotifera and Arcella sp. and Bacillariophyceae with a significance level alpha more than - 0.05. These results are similar to those found by (Haroon et al., 2020 ; Othman and Haroon, 2020) they recorded variable relations among epiphytes, macrophytes and bacteria at Damietta branch of Nile River and Nile River Rayahs.

\section{CONCLUSION}

The present study concluded that the distribution of flora and fauna along the Rosetta branch are affected by environmental conditions through seasonal changes of environmental characteristics as well as the interaction between these aquatic organisms. There are different positive relations between different types of flora and fauna refer to the power correlation between biological aspects at freshwater ecosystem, In addition, the quality of fresh water at the Rosetta Branch have deleterious effects by discharge water comes from several drains along the Rosetta branch thus exposed to different sources of pollution which were approved by the presence of indicator species of pollution. 

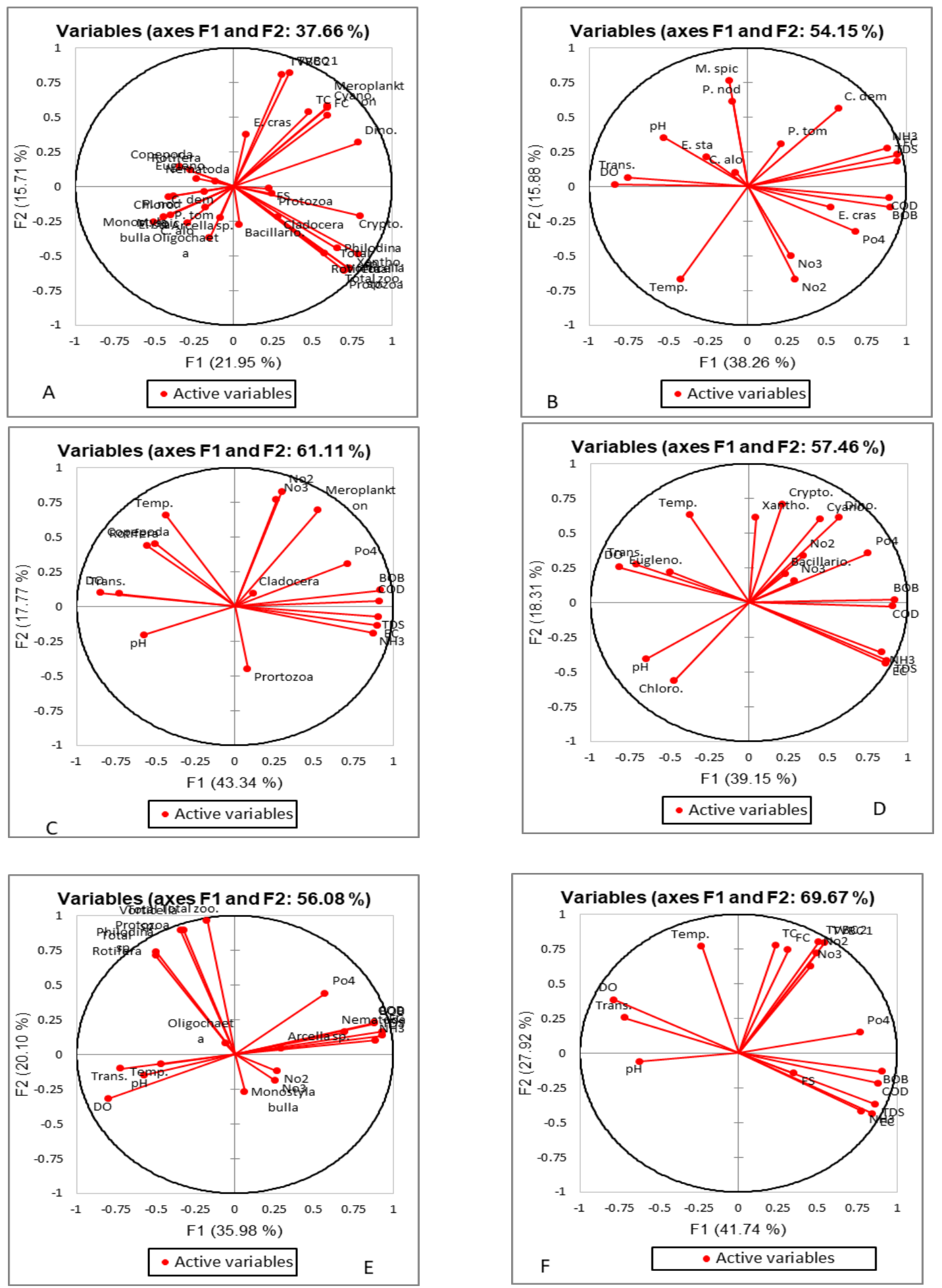

Fig.7. Principal Component Analysis performed on the relation between A) all biological Aspects (Bacteria, Macrophyte, Zooplankton, Microinvertebrates, and Microalgae), B) Macrophyte and Physico-chemical properties, C) Zooplankton and Physico-chemical properties, D) Microalgae and Physico-chemical properties, E) Microinvertebrates and Physico-chemical properties, F) Bacteria and Physico-chemical properties. 
TVBC1 $1=\mathrm{TVBC}$ at $37^{\circ} \mathrm{C}, \mathrm{TVBC} 2=\mathrm{TVBC}$ at $22^{\circ} \mathrm{C}, \mathrm{TC}=$ Total Coliform, $\mathrm{FC}=$ Fecal Coliform, FS $=\mathrm{Fecal}$ Streptococci, Temp.= Temperature, Trans.= Transparency, EC=Electrical Conductivity, TDS =Total dissolved solid, DO=Disolved Oxygen, BOD=Biological Oxygen Demand, COD=Chemical Oxygen Demand, $\mathrm{NH} 3=$ Ammonia, $\mathrm{No}_{2}=$ Nitrite, $\mathrm{No}_{3}=$ Nitrate, $\mathrm{Po}_{4}=$ ortho phosphorus, Total zoo.=Total Zooplankton, Bacillario.= Bacillariophyceae, Chloro.= Chlorophyceae, Cyano.= Cyanophyceae, Dino.= Dinophyceae, Eugleno.= Euglenophyceae, Crypto.= Cryptophyceae, Xantho. $=$ Xanthophyceae, M. spic= Myriophyllum spicatum, C. dem= Ceratophyllum demersum, E. cras= Eichhornia crassipes, P. nod= Potamogeton nodosus, E. $\mathrm{sta}=$ Echinochloa stagnina, C. alo= Cyperus alopecuroides, $\mathrm{P}$. tom= Polygonum tomentosum.

\section{ACKNOWLEDGEMENT}

This research is a part of project was supported and funded by National institute of Oceanography and fisheries (NIOF), Ministry of Higher Education and Scientific Research, Egypt, So that, the authors are most grateful to National institute of Oceanography and Fisheries Authority (NIOF, Cairo, Egypt) for funded this scientific project and providing all the necessary facilities to finish this project.

\section{REFERENCES}

Abd El-Karim, O.; Mohamed, M.S.; Khafagi, O.A. and Belal, D.M. (2016). Effect of substrate type on the response of diatoms to environmental gradients: Implication for bioassessment and biomonitoring programs. International Journal of Fisheries And Aquatic Studies, 4(2):361-369.

Abe, S.; Uchida, K.; Nagumo, T. and Tanaka, J. (2007). Alterations in the biomassspecific productivity of periphyton assemblages mediated by fish grazing. Freshwater Biology, 8 :1486-493

Adam, M. S.; Hifney A. F.; Fawzy M. A. and Al-Badaani A. A. (2017). Seasonal biodiversity and ecological studies on the epiphytic microalgae communities in polluted and unpolluted aquatic ecosystem at Assiut, Egypt. European Journal Of Ecology. 3(2) :92-106.

Afify, D. G.; Usama, M. T. and Mohammed, H. A. (2019). Water Quality Index and Microbial Assessment of Lake Qarun, El-Batts and El-Wadi Drains, Fayoum Province, Egypt. Egptian Journal of Aquatic Biology and Fisheries, 23(1) : 341 -357.

Ahmad, U.; Parveen, S.; Abdel Mola, H.R.; Kabir, H.A. and Ganai, A.H. (2012). Zooplankton population in relation to physico-chemical parameters of Lal Diggi pond of Aligarh (UP). India. J. Environ. Biol., 33 (6): 1015-1019.

Albay, M. and Akcaalan, R. (2003). Comparative study of periphyton colonisation on common reed (Phragmites australis) and artificial substrate in a shallow lake, Manyas, Turkey. Hydrobiologia, 506(1): 531-540.

Ali, M.A.; Mageed, A.A. and Heikal, M. (2007). Importance of aquatic macrophyte for invertebrate diverisity in large subtropical reservoir. Limnolgica, 37: 155- 169. 
Allen, H. L. (1971). Primary production, chemo-organotrophy and nutritional interactions of epiphytic algae and bacteria on macrophytes in the littoral of a lake. Ecol. Monogr., 41: 97-127.

Anufriieva, E.V.; Goher M.E.; Hussian, A.E.; El-Sayed S.M.; Hegab M.H.; Tahoun, U.M. and Shadrin, N.V. (2020). Ecosystems of artificial saline lakes. A case of Lake Magic in Wadi El-Rayan depression (Egypt). Knowl. Manag. Aquat. Ecosyst., 421: 31.

APHA, American Public Health Association (2005). Standard Methods for the Examination of Water and Wastewater, twenty first ed. Washington, D.C.

APHA, American public Health Association (2012). Standard methods for the examination of water and wastewater, 22nd ed. Washington, D.C.

Arora, J. and Mehra, N.K. (2003).Species diversity of planktonic and epiphytic rotifers in the Backwaters of the Delhi Segment of the Yamuna River, with remarks on new Records from India. Zoological Studies, 42 (2):239-247.

Azim, E. (1991): Food and feeding habits of Orechromis niloticus from different localites in Lake Nasser in spring and late summer. Asw. Sci. Tech. Bull., 12:115-142.

Badr, M.H.; Elewa, A.; Shehata, M.B.; Mohamed, L.F.and Abdelaziz, G.S. (2006). Studies on the effect of el-rahawy drain on the river nile water pollution by trace metals and major cations at el-kanater el-khyria area under the effect of seasonal variation. Bulletins of the Environmental Research, 9:35-54.

Balkhair K. S. (2016). Microbial contamination of vegetable crop and soil profile in arid regions under controlled application of domestic wastewater. Saudi journal of biological sciences, 23(1): S83-S92.

Benítez-Díaz, M. M.; María, E .C.; Gabriela, G.; María, J. F. and Marc P. (2014). Spatiotemporal variations of zooplankton community in a shallow tropical brackish lagoon (Sontecomapan, Veracruz, Mexico). Zool. Stud., 53: 59. https://doi.org/ $\underline{10.1186 / \mathrm{s} 40555-014-0059-6}$

Boulos, L. (2005). Flora of Egypt: (Monocotyledons). Al-Hadara Publishing, Cairo.Vol 4.

Bourrely. (1968). Les algues d' eau douce. Algues Jaunes brunes. Boubee and Cie, Paris, $438 \mathrm{pp}$.

Cabelli, V. (1978). New standards for enteric bacteria In: Mitchell, R. ed. Water Pollution Microbiology. John Wiley and Sons, New York, 2: 233-271.

Cattaneo, A.; Couillard, Y. ; Wunsam, S. and Michel C.M. (2004). Diatom taxonomic and morphological changes as indicators of metal pollution and recovery in Lac Dufault (Quebec, Canada). Journal of Paleolimnology, 32:163-175.

Cattaneo, A.; Galanti, G.; Gentinetta, S. and Romo, S. (1998). Epiphytic algae and macroinvertebrates on submerged and floating-leaved macrophytes in an Italian lake. Freshwater Biology, 4:725-40. 
Cattaneo, A.; Kerminian, T.; Roberge, M. and Marty, J. (1997).Periphyton distribution and abundance of substrata of different size along a gradient of stream trophy. Hydrobiol., 354: 101-110.

Cleve- Euler, A. (1952). Die Diatomeen von Schweden und Finland. Band 1, 2, 3, 4, and 5. Stockholm, Almqvist and Wiksells B oktryckeri AB.

Cook, G. (2007). Benthic diatoms in the Salinas of the Dry Creek saltfields, South Australia. Hydrobiologia, 576 (1): 61- 68.

Dang, P.D.; Khoi, N.V.; Nguyet, L.T.; Thanh, D.N. and Hai, H.T. (2015).Identification Handbook of Freshwater Zooplankton of the Mekong River and its Tributaries. Mekong River Commission, Vientiane. 207pp.

Dere, S.; Karacaoglu, D. and Dalkiran, N. (2002). A study on the epiphytic algae of the Nilüfer Stream (Bursa). Turkish Journal of Botany, 26: 219-234.

Difonzo, C. D. and Campbell, J.M. (1988).Spatial partitioning of microhabitats in littoral cladoceran communities. J. Freshwater Ecol., 4: 303-313.

Donia, N., (2005). Rosetta Branch Waste Load Allocation Model. 19th International Water Technology Conference, Sharm El-Sheikh, Egypt, 277-288.

Edberg, S. C.; Rice, E. W.; Karlin, R. J. and Allen, M. J. (2000). Escherichia coli the best biological drinking water indicator for public health protection. Journal of Applied Microbiology, 88: 1068-1168.

Edmondson, W.T. (1966). Freshwater Biology. $2^{\text {nd }}$ Edn. John Wiley and Sons. Inc. New York \& London.

Egyptian Standards (2007).Minister's Office, Egyptian Standards for potable water .Dissection No.(458) .

Einsle, U. (1996). Copepoda. Cyclopoida Guides the identification of the micro invertebrates of the continental waters of the world. Gustav Fisher Verlag, Stuttgart Jena New Yark, 81pp.

El-Amier, Y.A.; Zahran, M.A. and Al-Mamoori, S.O. (2015). Plant diversity of the Damietta Branch, River Nile, Egypt. Mesop. Environ., 1 (2): 109-129

El-Bahnasawy, M.A. (2013). Assessment of Gamma Irradiation on Antibiotic Resistant Bacteria Isolated from River Nile and Drainage Water in Egypt. Master Thesis, Botany \& Microbiology Dept. Fac. Sci., Al-Azhar University., Egypt.

El-Enany, H.R. (2009). Ecological studies on planktonic and epiphytic microinvertebrates in Lake Nasser, Egypt. Ph. D. Zool. Dept. Thesis, Fac. Sci. Banha Univ., 311pp.

El-Fadaly, H.; El-Defrawy, M.; El-Zawawy, F. and Makia, D. (2001): Chemical and microbiological evaluation of River Nile water in Dakahlia Governorate. Journal of Environmental Science, 22: 1-18.

EL-Sebaie, H.E.A.; Neveen, H. M.; Hanaa I. M.and Yasser, M. S. (2014). Biological Performance of Pterophyllum scalare larvae Fed on Artemia and Artificial Diet. World Journal of Fish and Marine Sciences, 6 (3): 289-294. 
El-Sheekh, M.M.; Haroon, A. M.and Sabae, S. (2018). Seasonal and spatial variation of aquatic macrophytes and phytoplankton community at El-Quanater El-Khayria River Nile, Egypt. Beni-Suef University J. Bas. Appl. Sci., 7: 344-352.

Fareed, M. F.; Haroon, A. M. and Rabh, S. A. (2008).Antimicrobial activity of some macrophytes from Lake Manzalah (Egypt). Pakis. J. Bio. Sc. 11 (21), 2454-2463.

Guerguess, S.K. (1993). Distribution of some rotifers in the Egyptian inland waters. Bulletin of NIOF, 19: 249-275.

Hany, M.and Shawky, Z. S. (2011): Microbial Pollution of Water in El-Salam Canal, Egypt. American-Eurasian J. Agric. \& Environ. Sci., 11 (2): 305-309.

Haroon, A. M. (2020a). Proximate and Total Fatty Acid Composition of Some Aquatic Macrophytes in the Nile River Rayahs, Egypt. Pak. J. Biol. Sci., 23: 295-305.

Haroon, A. M. (2020b). Factors affecting community structure, distribution pattern and chemical composition of aquatic macrophytes in El-Rayah El-Nasery and ElNoubaria Canal of Nile River, Egypt. Egypt. J. Aqua. Resear., 46(3): 235-244.

Haroon, A. M. and Abdel-Al, E. I. (2016). Chemical composition and in vitro anti-algal activity of Potamogeton crispus and Myriophyllum spicatum extracts. Egyptian Journal of Aquatic Research, 42: 393-404.

Haroon, A. M. and Daboor, S. M. (2019). Nutritional status, antimicrobial and antibiofilm activity of Potamogeton nodosus Poir. Egypt. J. of Aquat.Biol and Fish., 23(2): 81-93.

Haroon, A. M. and Hussian, A. M. (2017). Ecological assessment of the macrophytes and phytoplankton in El-Rayah Al-Behery, River Nile, Egypt. Egyptian J. of Aquat. Res., 43 (3): 195-203.

Haroon, A. M.; Tahoun, U. M.; Sabae, S. A. and Hamza, W. T. (2020). Biological Characterization of Water in Damietta Branch of the Nile River, Egypt. Pak. J. Biol. Sci., 23:861-882.

Hussian, A. M. and Haroon, A.M. (2019).Sensitivity of Submerged Aquatic Macrophytes and Their Epiphytic Microalgae to the Different Environmental Variables in River Nile, Egypt. International Journal of Ecology and Environmental Sciences .45, no 1 .

Iskaros, I.A.; Bishai, R. M. and Mokhtar, F. M. (2008). Seasonal variations of zooplankton and physico-chemical factors in Lake Nasser, Egypt. Egy. J. Aquat. Res.,34 (2): 232-259.

Jan, S.R. (1996). An introduction to algal ecology in freshwater benthic habitats. In: Stevenson, R.J., Bothwell, L.M. and Lowe, L.R. (eds): Algal ecology: Freshwater benthic ecosystem. Academic Press, London, 753pp.

Kimmel, D.G.; Roman, M.R. and Zhang, X. (2006). Spatial and Temporal Variability in Factors Affecting Mesozooplankton dynamics in Chesapeake Bay: Evidence from Biomass Size Spectra. Limnol. and Oceanogr., 51(1): 131-141. 
Koch, A.L. (1994). Growth measurement. In: Gerhardt, P., Murray, R.G.E., Wood, W.A., Kriegz, N.R. (Eds.), Methods for General and Molecular Biology. American Society for Microbiology, Washington, D.C., pp. 248-277.

Larson, C.A. and Passy, SI. (2012). Taxonomic and functional composition of the algal benthos exhibits similar successional trends in response to nutrient supply and current velocity. FEMS Microbiol. Ecol., 80(2): 352-362.

Leech, D.M.; Williamson, C.E.; Moeller, R.E. and Hargreaves, B.R. (2005). Effects of ultraviolet radiation on the seasonal vertical distribution of zooplankton: a database analysis. Archiv Fur Hydrobiologie, 162(4): 445-464.

Mageed, A. A. (2005). Effect of some environmental factors on the biodiversity of holozooplankton community in lakeqarun, Egypt. Egyp. J.of Aqua.Resear., 31(1): 230-234.

Misra, R. (1968). Ecology Work Book. Oxford and IBH Publishing, Calcutta. 244 pp.

Mizuno, T. (1990) Illustration of the Freshwater plankton of Japan. 9th printing. Hoikush publishing Co., LOT, Japan, 353 pp.

Mola, H.R. (2011).Seasonal and spatial distribution of Brachionus (Pallas, 1966; Eurotatoria: Monogonanta: Brachionidae), a bioindicator of eutrophication in lake ElManzalah, Egypt. Biology and Medicine, 3(2): 60-69.

Mola, H.R.; Shaldoum, F. M. and Alhussieny, A. M. (2018). Diversity of planktonic and epiphytic microinvertebrates associated with the macrophyte Eichhornia crassipes (Mart.) in River Nile at El-Qanater El-Khiria region, Egypt. J. Egypt. Acad. Soc. Environ. Develop., 19 (1): 117-132.

Noble, R.T.; Lee, I.M. and Schiff, K.C. (2004). Inactivation of indicator microorganisms from various sources of faecal contamination in sea water and fresh water. J. Appl.Microbiol., 96: 464- 472.

Ondrusek, M.E.; Bidigare, R.R.; Sweet, S.T.; Defreitas, D.A. and Brooks, J.M. (1991). Distribution of phytoplankton pigments in the North Pacific Ocean in relation to physical and optical variability. Deep-sea Research, 38: 243-266.

Oso, J.A.; Ayodele, I.A. and Fagbuaro, O. (2006). Food and Feeding Habits of Oreochromis niloticus (L.) and Sarotherodon galilaeus (L.) in a Tropical Reservoir. World J. Zool., 1 (2): 118-121.

Othman, A. A. and Haroon, A. M. (2020). Association between the Distributions and Chemical Composition of Aquatic Macrophytes and Bacterial Community Structure in Some Irrigation Canals (Rayahs) of the Nile River, Egypt. Egypt. J. Aqua. Biol.and Fish., 24(5): $639-660$.

Pearson, G.A. and Evans, L.V. (1990).Settlement and survival of Polysiphonia lanosa (Ceramiales) spores on Ascophyllum nodosum and Fucus vesiculosus (Fucales). Journal of Phycology, 26: 597-603.

Pennak, R.W. (1978). Freshwater Invertebrates of United States. (2 ${ }^{\text {nd }}$ Ed). John Wiley and Son. 
Prescott, A. G. (1978). Temperature and manganese as determining factor in the presence of diatoms or blue green algal flora in stream. Proc. Nat. Acad., 64:472 - 478.

Ramcharan, C.; Pangle, K.L. and Peacor, S.D. (2009). Light-dependent predation by the invertebrate planktivore Bythotrephes longimanus. Can. J. Fish. Aquat. Sci., 66(10): 1748-1757.

Robert, M.S. and Noel, R.K. (1981). General characterization. In: Manual of Methods for General Bacteriology. American Society for Microbiology, Washington, D.C, pp. 409-433.

Saad, A..A.; Mostafa, B.B.; El-Magd, S.S. and Azzam, A.M. (2012). Studies on some Bacterial species in certain River Nile sites at great Cairo,Egypt. Journal of Environmental Science, 10 (1): 25- 37.

Saad, A.; Emam, W.; El-Shabrawy, G. and Gowedar, F.(2013). Sewage pollution and zooplankton assemblages along the Rosetta Nile branch at El Rahawy area, Egypt. International journal of environmental science and engineering, 4: 29-45.

Sabae, S.Z. and Saleh, A. R. (2007). Evaluation Of The Microbial Quality Of The River Nile Waters At Damietta Branch, Egypt. Egypt. J. Aqua.Res., 33 (1): 301-311.

Safaa, M.; Hesham, M.; Mervat, A.; Essam, H. and Mostafa A. (2012).Water Quality Assessment of River Nile at Rosetta Branch:Impact of Drains Discharge. Middle-East Journal of Scientific Research, 12 (4): 413-423.

Sakuma, M; Hanazato, T. and Nakazato, R. (2002). Abundance of Chydoridae associated with plant surface, water column and bottom sediments in the macrophyte zone of a lake. Verh. Int. Verein. Limnol., 28.

Shaltout, K. H.; Eid, E. M.and El-Komil, T. M. (2016). Phytomass and nutrient value of Potamogeton crispus L. in the water courses of Nile Delta, Egypt. Rend. Fis. Acc. Lincei., 27: 251-259.

Shaltout, K.H.; Galal, T.M. and El- Komi, T. (2009). Evaluation of the nutrient status of some hydrophytes in the water courses of Nile Delta, Egypt. Journal of Botany, pages 11. , Article ID 862565 | https://doi.org/10.1155/2009/862565.

Shaltout, K.H.; Galal, T.M. and El- Komi, T. (2010). Evaluation of the nutrient status of some hydrophytes in the water courses of Nile Delta, Egypt. Ecologia Mediterranea, 36(1):77-86.

Shannon, C. D. and Weaver. W. (1963). The mathematical theory of communication.Univ. Illinois Press, Urbana

Shehata, S.M.; Shehata, K.K; Hussien, M.M. and Mageed, A.A. (1998a). Taxonomy, population structure, and species diversity of Rotifera in the high Dam Lake. Egypt J. Aquat. Biol. and Fish., 2 (1): 1-36.

Shehata, S.M.; Shehata, K.K; Hussien, M.M. and Mageed, A.A. (1998b). Taxonomical and ecological studies on some zooplankton species: Ciliata, Rhizopoda, Turbellaria and Crustacea of the High Dam Lake. Egypt J. Aquat. Biol. and Fish., 2(1): 37-63. 
Shiel, R. J. and Koste, W. (1992). Rotifera from Australian inland water. III: Trichocercidae. Trans. R. Soc. S. Aust., 116(1):1-37.

Shurin, J. B. (2000). Dispersal limitation, invasion resistance and the structure of pond zooplankton communities. Ecology. 81:3074-3086.

Smirnov, N.N. (1996). Cladocera: The chydorinae ans sayciinae (chydoridae) of the world. SPB Academic Publishing bv. 119pp.

Starmach, K. (1968). Flora of Slodkonda Polaki Tos.594 PP.

Totti, C.; Poulin M.; Romagnoli, T.; Perrone, C.; Pennesi. C.and DeStefano, M. (2009). Epiphytic diatom communities on intertidal seaweeds from Iceland. Polar Biol., 32:1681-1691.

Wahl, M. and Mark, O. (1999). The predominantly facultative nature of epibiosis: experimental and observational evidence. Mar. Ecol. Prog. Ser., 187: 59-66.

Wetzel, R. G. (1993). Microcommunities and microgradients: linking nutrient regeneration, microbial mutualism, and high sustained aquatic primary production. Aquatic Ecology, 27: 3-9.

Yehia, H.M. and Sabae, S.Z. (2011).Microbial pollution of water in El-Salam canal, Egypt. Amer. Eura. J. Agric. and Environ. Sci., 11 (2):305-309.

Zahran, M.A. and Willis, A. J. (1992). The vegetation of Egypt. Chapman and Hall, London, 424pp. 